\title{
Inflammatory cytokines and atrial fibrillation: current and prospective views
}

\author{
This article was published in the following Dove Press journal: \\ Journal of Inflammation Research \\ 28 August 2010 \\ Number of times this article has been viewed
}

\author{
Hadi AR Hadi \\ Alawi A Alsheikh-Ali \\ Wael AL Mahmeed \\ Jassim M Al Suwaidi \\ Institute of Cardiac Sciences, Sheikh \\ Khalifa Medical City, Abu Dhabi, \\ United Arab Emirates
}

\begin{abstract}
Atrial fibrillation (AF) is the most common sustained arrhythmia and a challenging clinical problem encountered in daily clinical practice. There is an increasing body of evidence linking inflammation to a broad spectrum of cardiovascular conditions including AF. Historical evidence supports an association between AF and inflammation and is consistent with the association of AF with inflammatory conditions of the heart, such as myocarditis and pericarditis. AF has been associated with myocardial oxidative stress, and antioxidant agents have demonstrated antiarrhythmic benefit in humans. Increased plasma interleukin (IL)-6, C-reactive protein (CRP), and plasma viscosity support the existence of an inflammatory state among "typical" populations with chronic AF. These indexes of inflammation are related to the prothrombotic state and may be linked to the clinical characteristics of the patients (underlying vascular disease and comorbidities), rather than simply to the presence of AF itself. It has been suggested that inflammation may have a role in the development of atrial arrhythmias after cardiac surgery, and that a genetic predisposition to develop postoperative complications exists. Cytokines can have a prognostic significance; IL-6 levels, CRP, and other cytokines may have prognostic value in AF. Cytokine lowering therapies, statins, angiotensin converting enzyme inhibitors and other anti-inflammatory agents may have a role in the treatment of AF. The present article provides an overview of the evidence linking inflammatory cytokines to $\mathrm{AF}$ and their therapeutic and prognostic implications.
\end{abstract}

Keywords: atrial fibrillation, inflammation, cytokines

\section{Introduction}

Atrial fibrillation (AF) is the most common sustained arrhythmia in clinical practice. Its prevalence is strongly age-dependent, affecting approximately $1 \%$ of persons less than 65 -years-old, and 5\% of individuals aged older than 65 years. AF is also associated with an increase in the relative risk of mortality in both men and women, ranging from 1.3 to 2.3 , independent of other risk factors, as well as an increasing morbidity and adverse affects on quality of life. In particular, patients who present with stroke in AF have a considerably worse outcome, defined by a higher mortality, morbidity, and longer hospital stays compared with patients who have a stroke in the absence of AF. ${ }^{1-5}$

There is an increasing body of evidence linking inflammation to a broad spectrum of cardiovascular conditions, such as coronary artery disease (CAD), insulin resistance, diabetes mellitus, and hypertension. In addition, there is emerging data to support an association between inflammation and AF. This has created exciting potential opportunities to target inflammatory processes for the prevention of AF.
Correspondence: Hadi AR Hadi, MD, FRCP (UK)

Institute of Cardiac Sciences, Sheikh Khalifa Medical City, PO Box 51900, Abu Dhabi, United Arab Emirates Tel +97 I 508192544

Fax+97 I2 6103489

Email hadi968@hotmail.com which permits unrestricted noncommercial use, provided the original work is properly cited. 
AF has been associated with myocardial oxidative stress, and antioxidant agents have demonstrated antiarrhythmic benefit in humans.

The structural changes of the atria that define structural remodeling in AF include left atrial dilatation and increasing atrial fibrosis. These structural changes typically occur in parallel with changes of the electrical properties of atrial tissue. ${ }^{6}$ In long-lasting persistent AF, lower levels of interleukin (IL)-6 and C-reactive protein (CRP) appear to be associated with maintenance of sinus rhythm after pharmacological cardioversion irrespective of the use of rennin-angiotensin system (RAS) inhibitors. ${ }^{7}$ Radiofrequency ablation generates a localized myocardial necrosis that might result in a release of inflammatory mediators. Limited studies have investigated this correlation between inflammatory cytokines and AF. Elevated IL-6 and CRP levels in patients with postoperative AF suggest inflammatory components have a role in the pathogenesis of post operative $\mathrm{AF}^{8}$ In addition, higher concentrations of serum IL-8 in coronary artery bypass graft $(\mathrm{CABG})$ patients with postoperative AF suggested a role for inflammation in the pathogenesis of AF after open heart surgery. ${ }^{9}$ Among AF patients, cytokines can have a prognostic significance.

The potential for using novel agents that can influence the inflammatory processes in AF may represent a shift in the way we think of this common arrhythmia, from an electrical to a more structural emphasis. ${ }^{10-12}$ Atrial biopsies from patients with AF have confirmed the presence of inflammation. Furthermore, there is preliminary evidence to support the use of a number of drug therapies that have the potential to reduce the clinical burden of AF. On the other hand, conflicting results exist on the activation of tissue cytokines in fibrillating atrial samples. ${ }^{13-15}$ The aim of this article is to present an overview of the evidence linking inflammatory cytokines to AF. We reviewed pertinent articles published on Medline, Pubmed, Scopus and EBSCOhost ${ }^{\circledR}$ research databases till December 2009, using the following indexing terms: inflammation, cytokines, AF, and atrial arrhythmias.

\section{Physiological and immunological perspectives Morphological cellular changes in atrial fibrillation}

The structural changes of the atria that define structural remodeling in AF include left atrial dilatation and increasing atrial fibrosis. These structural changes typically occur in parallel with changes of the electrical properties of atrial tissue. Key to this fibrotic process is the deposition of increased amounts of connective tissue, including collagen and fibronectin, between individual atrial myocytes. This leads to separation of myocytes from one another, and subsequent impairment of atrial conduction at the cellular level. All the above result in alterations in the biophysical properties of atrial tissue, allowing the initiation and perpetuation of AF. ${ }^{6,15-20}$

Atrial biopsies taken from patients in AF have demonstrated evidence of inflammatory infiltrates and oxidative damage within atrial tissue not seen in control subjects without AF. In one study, abnormal atrial histology was uniformly found in multiple biopsy specimens of 12 patients with lone AF, compared with normal histology in all of the controls, with $66 \%$ of the AF group showing evidence of occult myocarditis. This supports the view that inflammation is involved in the pathophysiology of AF. ${ }^{21}$ Recently, activation of the local RAS and mitogen-activated protein kinase (MAPK) pathways in atrial myocardium was found to play an important role in atrial structural remodeling related to AF. Another important mediator of the angiotensin II (Ang II) effect is the Janus kinase/signal transducers and activators of transcription (STAT) pathway, which has never been characterized in the atrium. In cultured atrial myocytes and fibroblasts, Ang II induced tyrosine phosphorylation of signal transducer and activator of transcription 3 (STAT3) through a Ras-related C3 botulinum toxin substrate 1 (Rac)1-dependent mechanism, which was inhibited by dominant-negative Rac1, losartan, and simvastatin. In atrial myocytes, activation of STAT3 by Rac1 was mediated by direct association of Rac1 with STAT3; however, in atrial fibroblasts, it was mediated by an indirect paracrine effect. Constitutively active STAT3 increased protein synthesis, and dominant-negative STAT3 abrogated Ang II-induced protein synthesis in atrial myocytes and fibroblasts. Rats infused with long term Ang II exhibited higher levels of activated Rac1, phospho-STAT3, collagen synthesis, and atrial fibrosis in the atria, all of which were attenuated by oral losartan and simvastatin. In human atrial tissues from patients with AF, Ang II and phospho-STAT3 levels were also elevated. The Ang II/ Rac1/STAT3 pathway is an important signaling pathway in the atrial myocardium thought to be involved in atrial structural remodeling. ${ }^{22} \mathrm{AF}$ has also been associated with myocardial oxidative stress, and antioxidant agents have demonstrated antiarrhythmic benefit in humans. ${ }^{23}$

\section{Oxidative stress and atrial fibrillation)}

Infection of endothelial cells with Chlamydia pneumoniae elicited the production of several inflammatory mediators including monocyte chemoattractant protein-1, IL-1, IL-8, 
Atrial fibrillation (permanent \& paroxysmal, post ablation, post cardioversion, post operative)

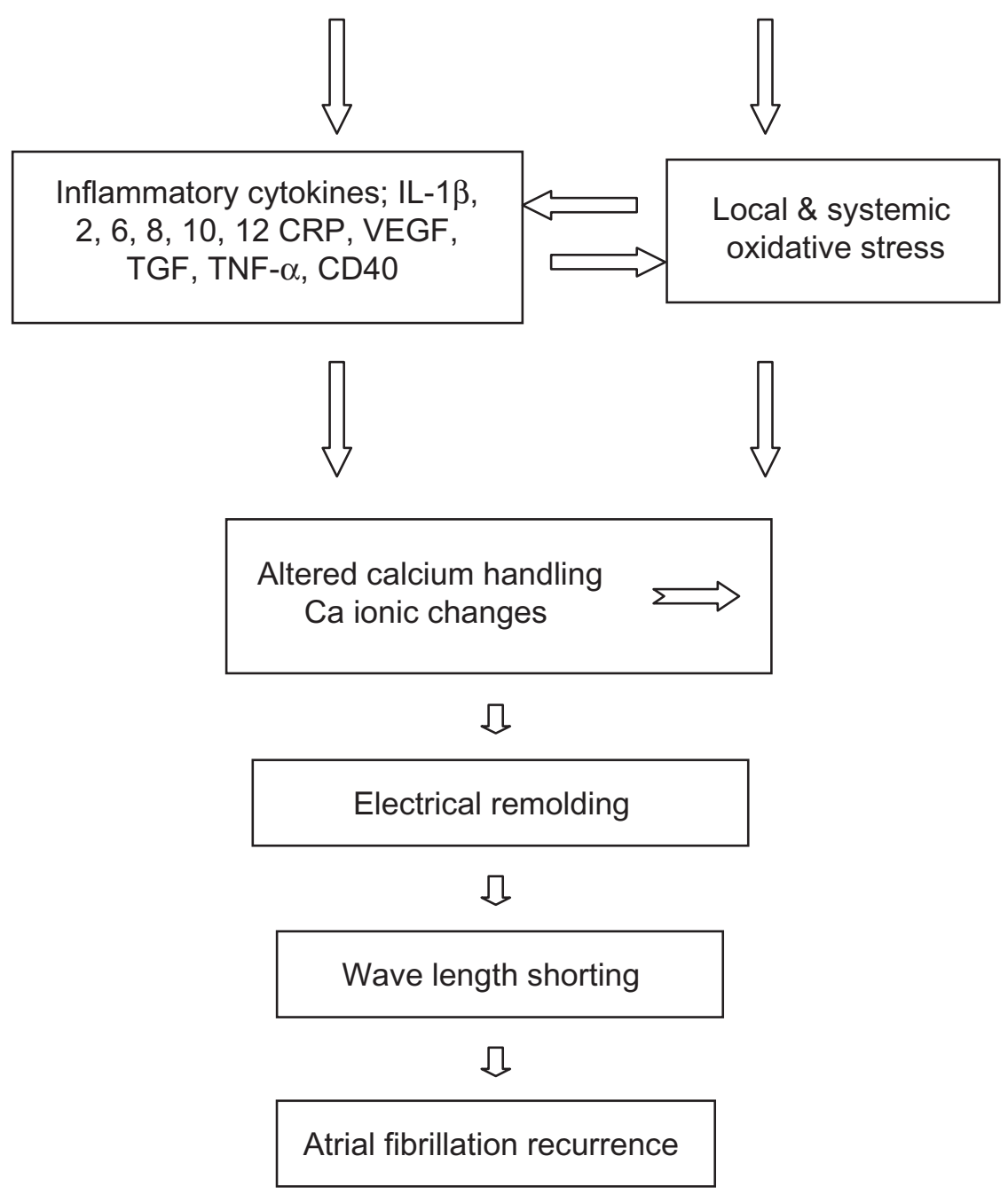

Figure I Role of inflammatory cytokines and oxidative stress in recurrence of atrial fibrillation.

Abbreviations: IL, interleukin; CRP, C-reactive protein; VEGF, vascular endothelial growth factor; TGF, transforming growth factor; TNF, tumor necrosis factor.

IL-18, tumor necrosis factor (TNF), interferon and soluble intercellular adhesion molecule (Figure 1). Most of these cytokines play a crucial role in inflammation and are thought to be associated with the initiation and maintenance of $\mathrm{AF}^{24}$ Tissue factor expression was observed in the endothelia of left atrial appendages obtained from seven patients with nonvalvular AF and cardiogenic thromboembolism. Histopathologically, inflammatory cells infiltrated the endocardium of all seven patients showing features of persistent myocarditis. Activated T cells $[15.3 \pm 9.4$ cells/high power field (HPF), (mean $\pm \mathrm{SD})$ vs control $2.2 \pm 4.4 / \mathrm{HPF}(P=0.0294)]$ and a few macrophages $[5.1 \pm 8.4$ cells/HPF vs control $2.4 \pm 3.5$ cells/HPF $(P=\mathrm{NS})]$ infiltrated the endocardium.
Tissue factor was overexpressed in the endothelia particularly in tissues containing inflammatory cells and denuded matrix of the endocardium, compared with the control group. Von Willebrand factor, but not tissue factor pathway inhibitor, was also overexpressed in these tissues. ${ }^{25}$ Concordant changes between matrix metalloproteinase (MMP)-expression and fibrosis during mitral valve disease, both in left atrium (LA) and right atrium (RA), suggest involvement of MMPs in structural atrial remodeling. AF itself did not contribute to altered fibrosis or MMP-expression in the LA. ${ }^{26}$ Lipopolysaccharide (LPS) infusion is a well established experimental model used to investigate host systemic inflammatory responses. A post hoc analysis of prospective data collected for 652 healthy 
men (mean age $27 \pm 5$ years, all without history of AF) LPS led to overall marked increases in high-sensitivity CRP, IL-6, TNF- $\alpha$, and neutrophil counts (all $P<0.0001$ ). There was no evidence of new-onset AF in the subjects challenged with LPS infusion. ${ }^{27}$

Atrial fibrillation (AF) has been associated with myocardial oxidative stress, and antioxidant agents have demonstrated antiarrhythmic benefit in humans. Neuman et $\mathrm{al}^{23}$ compared serum markers of oxidation and associated inflammation in individuals with or without AF. Using serum markers of oxidative stress and inflammation, 40 male individuals - with or without persistent or permanent AF - who were matched for age, sex, diabetes, and smoking status, known confounding variables, and measurements of oxidative stress, were compared in a cross-sectional, case-control design. In this study derivatives of reactive oxidative metabolites (DROMs) and ratios of oxidized to reduced glutathione (Eh GSH) and cysteine (Eh CySH) were used to quantify oxidative stress. The investigators also measured inflammatory markers, including high-sensitivity CRP, IL-1 and IL-6, and TNF. Univariate conditional logistical regression analysis showed that oxidative stress, but not inflammatory markers, were statistically associated with $\mathrm{AF}(P<0.05)$. The increase in the odds ratios for AF for $\mathrm{Eh} \mathrm{GSH,} \mathrm{Eh} \mathrm{CySH,}$ and DROMs were 6.1 (95\% CI, 1.3-28.3; $P=0.02), 13.6$ (95\% CI, 2.5-74.1; $P=0.01$ ), and 15.9 (95\% CI, 1.7-153.9; $P=0.02)$, respectively. In multivariate analysis corrected for statins and other AF risk factors there was a stronger correlation between Eh GSH and Eh CySH $(\mathrm{R}=0.66)$ than between Eh GSH and DROMs $(\mathrm{R}=0.41)$. This study has several limitations. First is the small sample size. Nevertheless, based on the oxidative stress measure with the weakest association to AF (Eh GSH), only 13 individuals in each group would have been necessary to have a $90 \%$ power to detect the observed difference in means with a two-sided test. Although the sample size was sufficient to show differences between groups in oxidative stress markers, the sample size was too small to allow firm conclusions about the relationship between inflammatory markers and AF, given their smaller means and higher standard deviations. Moreover, all participants in this study were males and predominantly white. The results may not hold true for females or individuals of other races. The effect of medications other than statins or the duration of AF on the strength of association between oxidative stress and AF were not evaluated. The net number of medications was not different between the two groups. This study does not make clear the source of oxidative stress or how oxidative stress is related to AF.
As noted above, AF has been associated with cardiac oxidative stress, but a recent trial suggests that oxidative stress in AF may be more widespread. Therefore, it is possible that systemic oxidative stress contributes to AF risk, and, once AF is established, local cardiac oxidative stress reinforces the risk. ${ }^{52,28-39}$ Interestingly, congestive heart failure and hypertension are associated with oxidative stress, ${ }^{30-31}$ perhaps contributing to their unequal distribution between the two groups with and without AF. Finally, the investigators measured marker concentrations during usual clinical hours and without fasting, mimicking the most common clinical scenario. Measuring at other times or under other conditions may affect the results, but there is no known diurnal variation in DROM concentrations. There does appear to be diurnal variation of plasma-reduced thiols related to meals in animals, but the effect of this variation on the ratio of oxidized-to-reduced thiols is unknown. In preliminary studies, diurnal variations in Eh GSH and Eh $\mathrm{CySH}$ were too small to explain this study's results and have peaks that are separated by 6-7 h, suggesting that the differences observed were not the result of these variations alone. ${ }^{32}$

\section{Different cytokines and atrial fibrillation}

Seko et $\mathrm{al}^{33}$ reported that pulsatile mechanical stretch in vitro induced rapid secretion of vascular endothelial growth factor (VEGF) by cultured cardiac myocytes and that the stretch-induced secretion of VEGF was mainly mediated by secretion of transforming growth factor (TGF)- $\beta 1$ by cardiac myocytes in an autocrine fashion (Tables 1 and 2). The above author investigated the serum levels of VEGF and TGF- $\beta 1$ in patients with AF undergoing defibrillation therapy. The serum VEGF level before defibrillation was significantly increased in 13 out of 20 patients $(89.48 \pm$ $16.09 \mathrm{pg} / \mathrm{mL}$ [mean \pm standard error of mean, (SE)]). After defibrillation, the serum VEGF level in these 13 patients significantly $(P=0.019)$ decreased $(65.04 \pm 16.61 \mathrm{pg} / \mathrm{mL}$ $[$ mean $\pm \mathrm{SE}])$. The serum TGF- $\beta 1$ level before defibrillation therapy $(13.01 \pm 1.97 \mathrm{pg} / \mathrm{mL}[$ mean $\pm \mathrm{SE}])$ in these 12 patients also decreased after defibrillation therapy $(11.47 \pm 2.06 \mathrm{pg} / \mathrm{mL}$ [mean $\pm \mathrm{SE}])$. The changes in serum VEGF level significantly correlated with those in the serum TGF- $\beta 1$ level in these 12 patients $(\mathrm{R}=0.73, P<0.05$, $\mathrm{N}=12$ ). These data suggest that tachyarrhythmia-induced mechanical overload can increase the serum VEGF level, which can be a useful clinical marker for relative myocardial oxygen shortage in such patients. Tachycardia-induced mechanical overload could increase serum VEGF levels in 


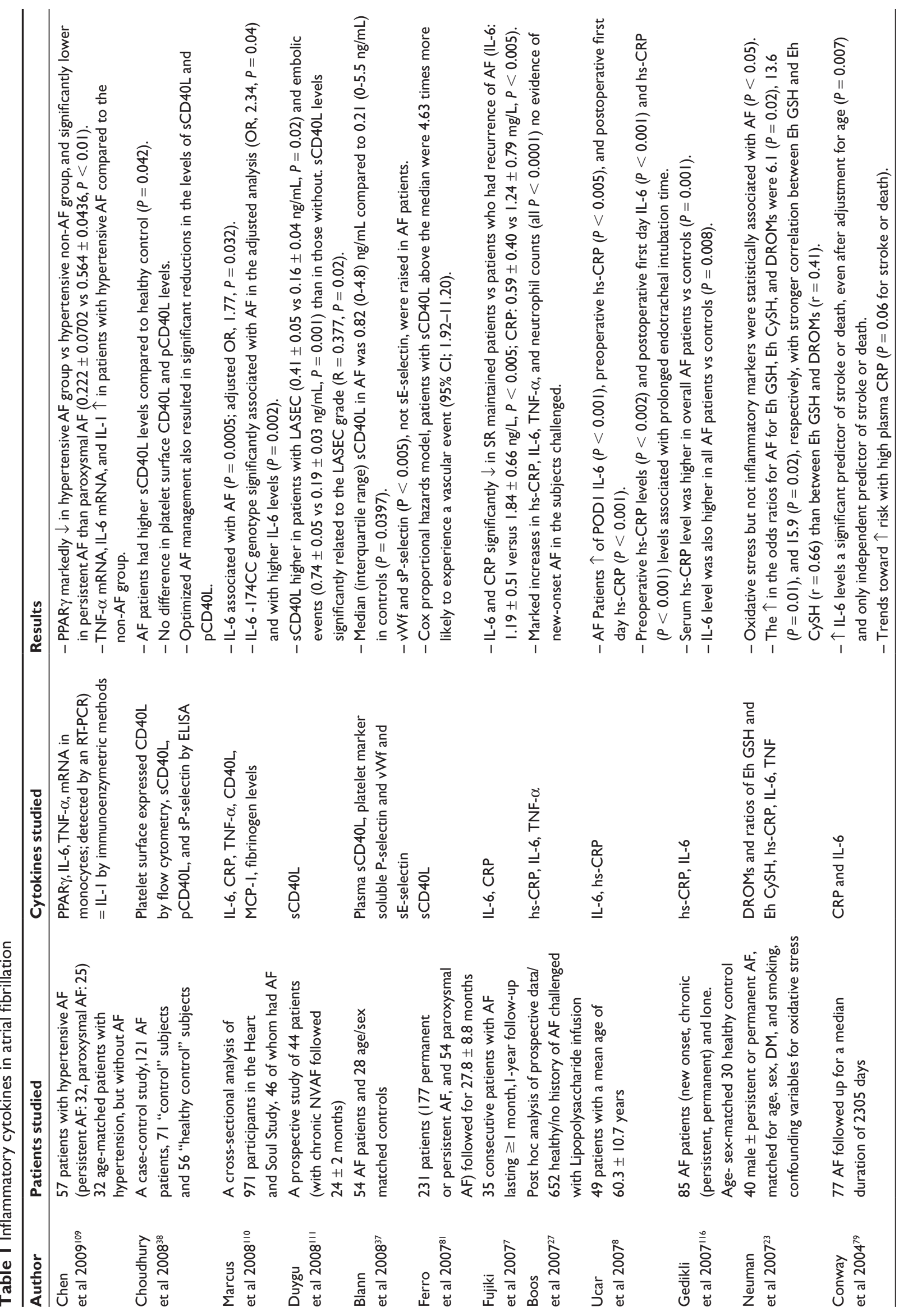




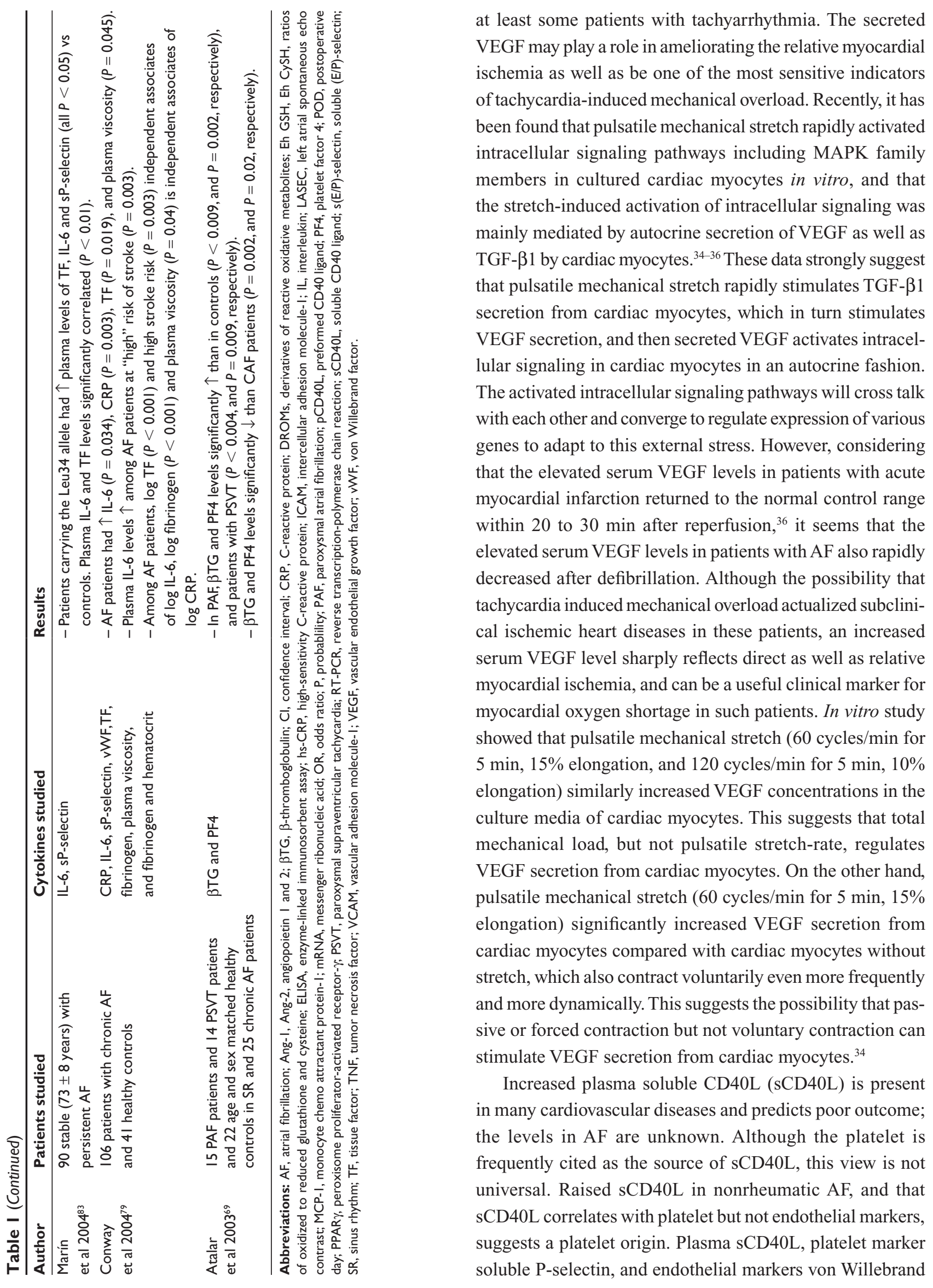


factor (vWf) and soluble E-selectin, were measured by enzyme-linked immunosorbent assay (ELISA) in $54 \mathrm{AF}$ patients free of diabetes or major cardiovascular disease, and in 28 age/sex matched controls. Median (interquartile range) $\mathrm{sCD} 40 \mathrm{~L}$ in AF was $0.82(0-4.8) \mathrm{ng} / \mathrm{mL}$ compared to 0.21 $(0-5.5 \mathrm{ng} / \mathrm{mL})$ in controls $(P=0.0397)$. vWf and soluble P-selectin $(P<0.005)$, but not soluble E-selectin, were raised in $\mathrm{AF}$, but none of the indices intercorrelated significantly. sCD40L is marginally raised in AF but the stimulus for this is unclear. The lack of clear correlation with relevant plasma markers suggests that the source is unlikely to be the endothelium or platelet alone. ${ }^{37}$ In a case-control study of 121 patients with AF, (71 "disease control subjects," and 56 "healthy control subjects"), AF patients had significantly higher $\mathrm{sCD} 40 \mathrm{~L}$ levels compared to healthy control subjects $(P=0.042)$, with no difference in platelet surface CD40L and preformed (p)CD40L levels (total amount of CD40L per platelet). A positive correlation was noted between levels of $\mathrm{sCD} 40 \mathrm{~L}$ and $\mathrm{pCD} 40 \mathrm{~L}$, and not with soluble P-selectin. CD40L-related indexes failed to distinguish between highrisk and low-risk AF patients. AF patients receiving optimal antithrombotic therapy had significantly lower pCD40L levels $(P<0.001)$ compared to control subjects. Optimized $\mathrm{AF}$ management also resulted in significant reductions in the levels of sCD40L $(P=0.023)$ and pCD40L $(P<0.001)$. While there is a significant, albeit modest, excess of platelet activation in AF patients (as measured by sCD40L levels) compared to healthy control subjects, this is not in excess of that seen in patients with underlying cardiovascular diseases..$^{38}$

\section{Interleukin 6 in atrial fibrillation}

IL-6 is a pleiotropic cytokine that has diverse physiological roles, including mediation of both proinflammatory responses and cytoprotective functions (Table 1). Major studies that have investigated the relationship between IL-6 and AF have shown significant correlation between the two. In a crosssectional analysis of 971 participants in the Heart Soul Study, 46 of whom had AF, IL-6 was the only biomarker significantly associated with AF (median IL-6 3.76 and $2.52 \mathrm{pg} / \mathrm{mL}$ in those with and without AF, respectively, $P=0.0005$; adjusted odds ratio $1.77, P=0.032$ ). The IL-6-174CC genotype was significantly associated with the presence of AF in the adjusted analysis (odds ratio $2.34, P=0.04$ ) and with higher IL-6 levels $(P=0.002)$. In the same study, no associations were found with other biomarkers, including CRP. ${ }^{39}$

Whereas in another study, 85 consecutive patients with AF serum, high sensitivity (hs)-CRP level was higher in overall AF patients than in controls $(0.63 \pm 0.57 \mathrm{vs}$ $0.23 \pm 0.1 \mathrm{mg} / \mathrm{dL}, P=0.001)$. Similarly, IL-6 level was also higher in all AF patients compared with controls $(29 \pm 36$ vs $11.6 \pm 9.7 \mathrm{pg} / \mathrm{mL}, P=0.008)$. In subgroup analysis, hs-CRP and IL-6 levels were significantly higher in both chronic $(0.69 \pm 0.62$ vs $0.23 \pm 0.1 \mathrm{mg} / \mathrm{dL}, P=0.001 ; 30 \pm 39$ vs $11.6 \pm 9.7 \mathrm{pg} / \mathrm{mL}, P=0.001$, respectively) and new onset AF patients $(0.51 \pm 0.46$ vs $0.23 \pm 0.1 \mathrm{mg} / \mathrm{dL}, P=0.003$; $28.4 \pm 31$ vs $11.6 \pm 9.7 \mathrm{pg} / \mathrm{mL}, P=0.009$, respectively) compared with controls. These markers were not different in new onset and chronic AF subgroups. On the other hand, hs-CRP and IL-6 levels tended to be high in lone AF patients $(P=0.06)$. The presence of AF was an independent factor for hs-CRP $(\mathrm{OR}=0.35,95 \% \mathrm{CI}=0.1-0.61, P=0.005)$ and IL-6 $(\mathrm{OR}=17,95 \% \mathrm{CI}=1-37, P=0.037) .{ }^{40}$

Whether inflammation is a cause or consequence of $\mathrm{AF}$ is uncertain. Sata et al measured hs-CRP, IL-6, TNF- $\alpha$ before and after pharmacological cardioversion in 15 patients with paroxysmal AF. Levels of hs-CRP, IL-6, and TNF- $\alpha$ after cardioversion were significantly higher in AF patients than those in controls $(P<0.05)$. Furthermore, the levels of these indices did not differ significantly even at 24 hours and 2 weeks after cardioversion. The limitations of the study are the small patient sample size, absence of a histological examination of the atrium, and the lack of inflammatory parameters before the onset of AF. Hence, additional studies in a larger patient cohort are required to resolve these limitations. Although atrial function (functional remodeling) may not recover in two weeks, the correlation between inflammation and atrial function is believed to be low. In future studies, it will be necessary to investigate the correlation between inflammation and the recovery of atrial function. Because inflammation may be caused by other factors, and the other causes of AF remain largely unknown. ${ }^{41}$

AF produces a characteristic profile of gene-expression changes that may be related to the pathophysiology of the arrhythmia. This has been demonstrated in right atrial appendages from 11 patients with chronic AF and underlying valvular heart disease (AF-VHD) and seven patients in sinus rhythm (SR) with VHD (SR-VHD) who were individually compared to an age-matched sinus-rhythm control group (SR-CTRL, 11 patients) using cardiac-specific microarray analysis (confirmed by quantitative polymerase chain reaction [PCR]). Out of 3863 analyzed genes, 832 genes were differentially expressed between SR-VHD and SRCTRL patients, and 169 genes were differentially expressed between AF-VHD and SR-VHD patients. AF-related changes included altered expression of nine genes pointing towards 


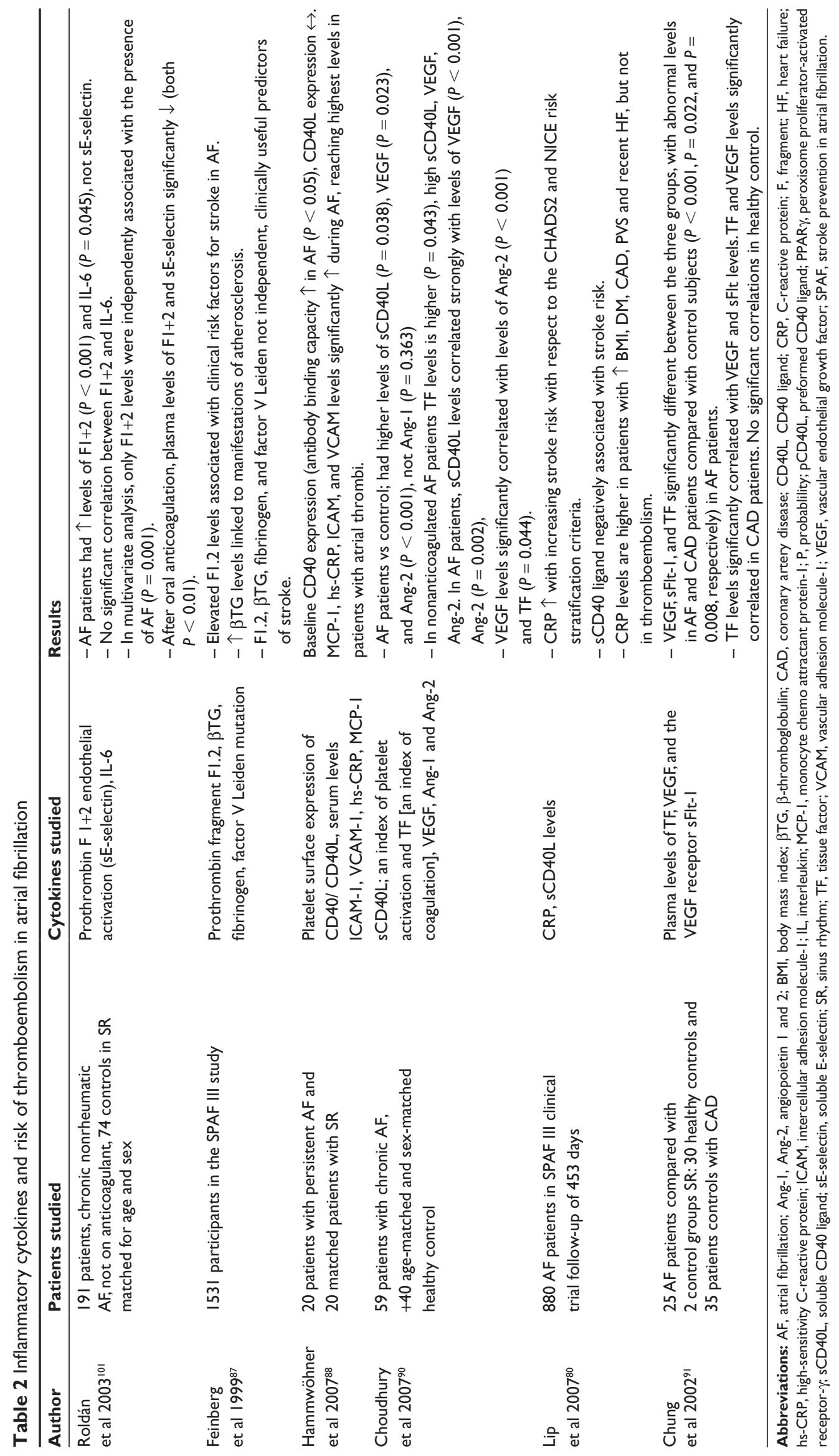


the development of fibrosis (eg, upregulation of TGF- $\beta 1$ ), and changes in eight genes potentially related to an increased risk of thromboembolic events (eg, upregulation of $\alpha-2$ macroglobulin $[\alpha 2 \mathrm{~m}]){ }^{42}$

\section{Atrial fibrillation and inflammation: role of C-reactive protein}

CRP has both proinflammatory and anti-inflammatory actions. Proinflammatory effects include the induction in monocytes of inflammatory cytokines and tissue factor and shedding of the IL-6 receptor. The association between AF and inflammation is suggested by the frequent association of AF with inflammatory conditions of the heart, such as myocarditis and pericarditis. ${ }^{43,44}$

Bruins and colleagues ${ }^{13}$ were the first to propose the inflammation-AF hypothesis, following their observations of an increased frequency of AF after coronary artery bypass surgery. They noted that the peak incidence of AF occurred on the second and third postoperative days, which coincided with the peak elevation of CRP levels. In an interesting study by Maixent and colleagues ${ }^{45}$ the authors demonstrated the presence of circulating autoantibodies against myosin heavy chain in a significant percentage of patients with idiopathic paroxysmal AF, which raises the possibility of an inflammatory autoimmune process in some patients with paroxysmal AF.

CRP, a biomarker of inflammation, has been reported to be elevated in some patients with AF. Statins and antioxidants may prevent AF through anti-inflammatory and/ or antioxidant effects. ${ }^{40,46-51}$ The precise mechanism for the increased circulating levels of CRP in AF is uncertain, but might reflect active participation of CRP in the local inflammatory response within the atrial myocardium. In patients with AF, CRP may localize in atrial tissue, possibly binding to the membranes of myocardial cells in inflamed tissues and activating complement, leading to tissue damage. ${ }^{52,53}$ Serum levels of hs-CRP have been noted to be higher among patients with AF compared with controls in sinus rhythm. ${ }^{23,47,54-58}$ hs-CRP has also been shown to be predictive of subsequent development of AF among a large cohort of patients in sinus rhythm at baseline. In addition, patients with persistent AF have higher hs-CRP levels than patients with paroxysmal $\mathrm{AF}$, and both groups have higher levels than controls without $\mathrm{AF}^{48}$ In one study, the combination of microalbuminuria and an elevated hs-CRP increased the risk of subsequent AF development by up to four-fold. ${ }^{59}$

Furthermore, a longer duration of AF is associated with higher hs-CRP levels and larger left atrial dimensions, supporting a link between the burden of AF, inflammation, and structural remodeling. In both cross sectional and longitudinal studies, hs-CRP has been consistently and significantly predictive of early AF relapse after successful cardioversion, even after adjustment for risk factors for AF, such as hypertension and CAD. Furthermore ablation induces an acute inflammatory upregulation reflected by an increase of CRP and fibrinogen levels and of the leukocyte count..$^{50,22,58,14,60,61}$

\section{Inflammatory cytokines and atrial fibrillation in experimental studies}

Inflammation and abnormal calcium homeostasis play important roles in AF. In isolated rabbit pulmonary vein (PV) cardiomyocytes, TNF- $\alpha$, a proinflammatory cytokine, can increase PV arrhythmogenicity and induce an abnormal calcium homeostasis, thereby causing inflammation-related AF (Table 3). Compared with control PV cardiomyocytes $(\mathrm{N}=45)$, the TNF- $\alpha$-treated PV cardiomyocytes $(\mathrm{N}=28)$ had significantly larger amplitudes of delayed after depolarizations, smaller L-type calcium currents, larger transient inward currents, larger $\mathrm{Na}(+)-\mathrm{Ca}(2+)$ exchanger currents, a smaller intracellular calcium transient, smaller sarcoplasmic reticulum calcium content, larger diastolic intracellular calcium, a longer decay portion of the calcium transient (Tau), and a decreased sarcoplasmic reticulum adenosine triphosphate (ATP)ase expression. ${ }^{62}$

Recombinant human (rh)IL-11 in old rats induces agedependent atrial remodeling manifested by atrial stretch and reduced atrial refractoriness, which favor AF. Na retention is the most likely mechanism underlying this effect of rhIL-11. ${ }^{63}$ Whether increased fibrosis in atrial tissue without ventricular fibrosis is sufficient to produce a substrate for AF was evaluated by Verheule et al. ${ }^{64}$ The authors studied cardiac electrophysiology (EP) and inducibility of atrial arrhythmias in major histocompatibility complex (MHC)-transforming growth factor (TGF)-cys33ser transgenic mice (Tx), which have increased fibrosis in the atrium but not in the ventricles. In anesthetized mice, wild-type (Wt) and $\mathrm{Tx}$ did not show significant differences in surface electrocardiogram (ECG) parameters. With transesophageal atrial pacing, no significant differences were observed in EP parameters, except for a significant decrease in corrected sinus node recovery time in Tx mice. Burst pacing induced AF in 14 of 29 Tx mice, whereas AF was not induced in Wt littermates $(P<0.01)$. In Langendorff perfused hearts, atrial conduction was studied using a 16-electrode array. Epicardial conduction velocity was significantly decreased in the Tx RA compared with 


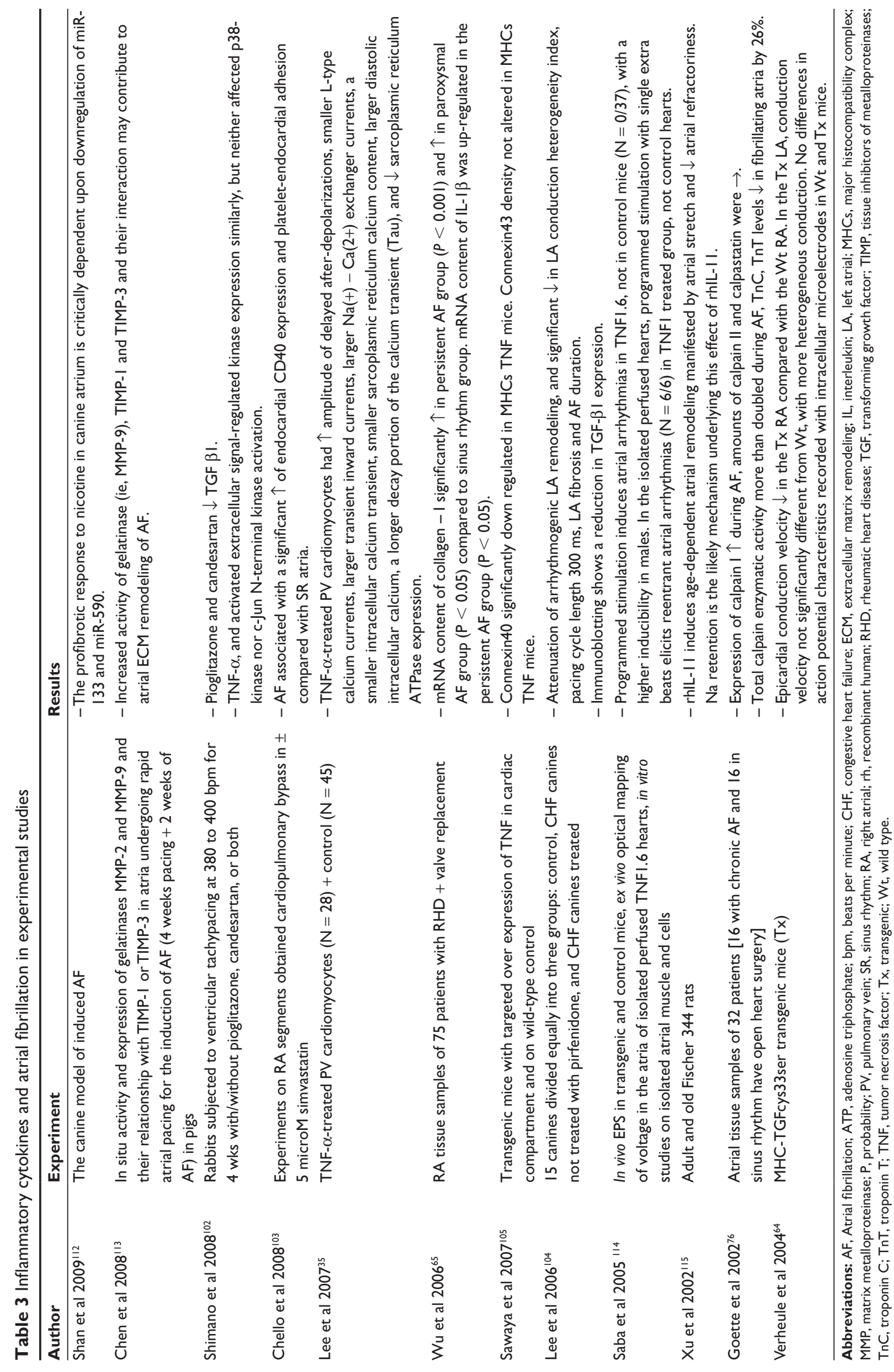


the Wt RA. In the Tx LA, conduction velocity was not significantly different from $\mathrm{Wt}$, but conduction was more heterogeneous. Action potential characteristics recorded with intracellular microelectrodes did not reveal differences between Wt and Tx mice in either atrium. Thus, in this transgenic mouse model, selective atrial fibrosis was sufficient to increase AF inducibility.

In human studies, gene expression of collagen type I and IL- $1 \beta$ is altered in patients with AF. Right atrial tissue samples were taken from 75 patients with rheumatic heart disease who underwent heart valve replacement surgery. The messenger ribonucleic acid (mRNA) content of collagen type I was significantly increased in the persistent AF group $(P<0.001)$ and increased in the paroxysmal AF group $(P<0.05)$ as compared with that in the sinus rhythm group. The mRNA content of IL-1 $\beta$ was up-regulated in the persistent AF group $(P<0.05) .{ }^{65}$

\section{Clinical perspectives Role of cytokines after cardioversion}

In long-lasting persistent AF, lower levels of IL-6 and CRP appear to be associated with maintenance of sinus rhythm after pharmacological cardioversion irrespective of the use of RAS inhibitors. In 35 consecutive patients with $\mathrm{AF}^{7}$ lasting $\geq$ 1 month who had successful pharmacological cardioversion with bepridil alone or in combination with aprindine, both plasma levels of IL-6 and CRP were significantly lower in 20 patients who maintained sinus rhythm than in 15 patients who had recurrence of AF (IL-6: $1.19 \pm 0.51$ versus $1.84 \pm$ $0.66 \mathrm{ng} / \mathrm{L}, P<0.005$; CRP: $0.59 \pm 0.40$ versus $1.24 \pm$ $0.79 \mathrm{mg} / \mathrm{L}, P<0.005)$. In another study in patients with hypertension and/or chronic stable CAD and symptomatic recent onset AF (86 patients), low serum IL-2 levels on admission were associated with successful cardioversion with amiodarone. Multivariate logistic regression analysis showed that lower IL-2 admission levels were a powerful independent predictor for successful cardioversion (OR: 0.154, 95\% CI: $0.043-0.552, P=0.004)$. This observation highlights the role of inflammation in AF and might have further prognostic and therapeutic implications. ${ }^{66}$

Inflammatory markers, and their role in maintaining sinus rhythm after electrical cardioversion for AF, and the effect of candesartan were investigated in a double-blind placebocontrolled study Candesartan in the Prevention of Relapsing Atrial Fibrillation (CAPRAF) ${ }^{67}$ in which 171 patients with persistent AF were randomly assigned to receive candesartan $8 \mathrm{mg} /$ day or placebo for 3 to 6 weeks before, and candesartan $16 \mathrm{mg} /$ day or placebo for 6 months after, electrical cardioversion, Compared with patients with a relapse of AF, patients who maintained sinus rhythm at 6 months after cardioversion $(\mathrm{N}=40)$ had lower baseline hs-CRP and E-selectin levels: median $2.36 \mathrm{mg} / \mathrm{L}$ (25th, 75th percentiles $1.28,4.09)$ versus $3.44 \mathrm{mg} / \mathrm{L}$ (25th, 75th percentiles 1.66 , $6.05, P=0.031)$ and $32 \mathrm{ng} / \mathrm{mL}(25 \mathrm{th}, 75$ th percentiles 23,42$)$ versus $37 \mathrm{ng} / \mathrm{mL}$ (25th, 75th percentiles 28, 51, $P=0.042$ ), respectively. Neither sustained sinus rhythm for 6 months nor did treatment with candesartan have an impact on measured concentrations of markers of inflammation. The CAPRAF study concluded that low hs-CRP and E-selectin at baseline were associated with maintenance of sinus rhythm after electrical cardioversion.

Serum hepatocyte growth factor (HGF) is considered to be a potent marker of vascular endothelial injury. Serum HGF levels increase in AF and decrease after successful direct-current (DC) cardioversion. Katoh et $\mathrm{al}^{68}$ studied 39 patients with AF in whom sinus rhythm was maintained for at least 7 days after DC cardioversion. Serum HGF levels were significantly higher in the AF patients (both lone $\mathrm{AF}$ and with underlying heart disease) than in the controls $(0.16 \pm 0.07$ vs $0.10 \pm 0.04 \mathrm{ng} / \mathrm{mL} ; P<0.001)$. Seven days after successful DC cardioversion, the patients' serum HGF levels had decreased significantly $(0.16 \pm 0.07$ vs $0.12 \pm$ $0.06 \mathrm{ng} / \mathrm{mL} ; P<0.05)$ and in the 24 patients maintaining sinus rhythm 1 month after DC cardioversion, serum HGF levels decreased to control values $(0.10 \pm 0.08 \mathrm{ng} / \mathrm{mL}$ at 1 month). Serum HGF levels of the 15 patients who had relapsed into AF 1 month after DC cardioversion tended to decrease 7 days after DC cardioversion, but increased again 1 month after DC cardioversion. This study is the first to demonstrate that serum HGF levels increase in AF and decrease after successful DC cardioversion. This may reflect the fact that AF induces vascular endothelial injury. In another study the levels of $\beta$-thromboglobulin ( $\beta \mathrm{TG})$ and platelet factor 4 (PF4) during tachyarrhythmia (in 15 patients with paroxysmal AF [PAF] [9 men, mean age $45 \pm 11$ ], and 14 patients with paroxysmal supraventricular tachycardia [PSVT] [8 men, mean age $40 \pm 10]$ ), there was no platelet activation in patients with PSVT during tachyarrhythmia, but significantly increased platelet activity in paroxysmal AF and chronic AF patients. There was a significant decrement of the platelet activity to a level of control subjects 24 hours after cardioversion of PAF. ${ }^{69}$

Abnormal hemorheology appears to play an important role in patients with paroxysmal AF, especially during the paroxysms of AF. Cardioversion of persistent AF to sinus rhythm appears to decrease the platelet activation, 
but whether this translates into a beneficial reduction in thromboembolic risk is unknown. ${ }^{70}$ Injury to the heart causes hematopoietic progenitor cells (HPCs) to migrate to the site of damage and to undergo cell differentiation. Studies suggest that myocardial progenitor cells invade atrial tissue. So far it is unclear, however, whether an atrial disease per se affects circulating HPCs. In a small sample size study of 17 patients with persistent AF, 12 with PAF, and 17 matched patients with sinus rhythm, HPCs (CD34 and CD34+/CD117+) were quantified with the use of a fluorescence-activated cell sorter; stromal cell derived (SDF) factor-1 (SDF-1 $\alpha$ ), VEGF, and atrial natriuretic peptide (ANP), were determined by immunoassays. In patients with persistent AF, blood samples obtained before as well as 10 minutes, 24 hours, and 48 hours after electrical cardioversion CD34+ HPCs $(P<0.01)$ were increased during persistent AF only. Highest SDF-1 $\alpha$ levels were also observed during persistent AF. Successful and unsuccessful cardioversion decreased CD34+ HPCs temporarily $(P=0.05)$. Forty-eight hours after successful cardioversion, SDF-1 and CD34+ HPC levels started to decline, reaching control levels after $59 \pm 19$ days. CD34+/CD117+ and VEGF levels were increased by DC energy but not by AF. ANP levels correlated with $\mathrm{CD} 34+\mathrm{HPC}(\mathrm{R}=0.76 ; P=0.01)$ and SDF-1 $\alpha(\mathrm{R}=0.56 ; P=0.01)$. HPCs from patients with AF had a greater tendency to differentiate into cells expressing cardiomyocyte markers ANP and myocyte enhancer factor- 2 . Persistent AF appears to increase the potential of HPCs for cardiomyogenesis. Restitution of CD34+ HPC levels, mediated by SDF-1 and possibly ANP, occurs within several weeks after successful cardioversion. ${ }^{71}$

\section{Role of cytokines after atrial fibrillation ablation}

Radiofrequency ablation generates a localized myocardial necrosis that might result in a release of inflammatory mediators (Table 4). Limited studies have investigated the potential role of inflammatory cytokines and catheter-based radiofrequency ablation of AF. Liuba et al ${ }^{72}$ studied 29 patients referred for radiofrequency catheter ablation: 10 patients with paroxysmal AF, 8 patients with permanent AF, and 10 control patients with Wolff-Parkinson-White (WPW) syndrome and no evidence of AF (mean age $54 \pm 11$ vs $57 \pm 13$ vs $43 \pm 16$ ). Compared with controls and patients with paroxysmal AF, patients with permanent AF had higher plasma levels of IL-8 in the samples from the femoral vein, right atrium, and coronary sinus, but not in the samples from the pulmonary veins (median values in the femoral vein: 2.58 vs 2.97 vs $4.66 \mathrm{pg} / \mathrm{mL}, P=0.003$; right atrium: $2.30 \mathrm{vs}$
3.06 vs $3.93 \mathrm{pg} / \mathrm{mL}, P=0.013$; coronary sinus: 2.85 vs 3.15 vs $4.07, P=0.016)$. A high degree of correlation existed between the IL- 8 levels in these samples (correlation coefficient between 0.929 and $0.976, P<0.05$ ). No differences in the CRP and IL-6 levels were noted between the three groups of patients.

IL-6, IL-1 $\beta$, TNF- $\alpha$, IL-8, IL-10, and IL-12, and SDF-1 were measured by immunoassay by Stein et $\mathrm{al}^{73}$ in patients with paroxysmal AF before and after PV isolation. CD34+, CD133+, CD117+, and endothelial progenitor cells (EPCs) were analysed by flow cytometry and culture assay. Myocardial necrosis and inflammatory response correlated with an increase in IL-6 $(P=0.007)$. In contrast, SDF-1 levels decreased after radiofrequency ablation $(P=0.004)$. Yet, no significant changes were observed in IL- $1 \beta$, TNF- $\alpha$, IL-8, IL-10, and IL-12 plasma levels or in the number of circulating CD34+, CD133+ and CD117+ progenitor cells.

CRP and IL-6 levels are also elevated in patients presenting in atrial flutter (AFL). Given the lower coronary sinus concentrations of these inflammatory markers in such patients, their origin appears to be systemic rather than cardiac. This was shown in a prospective observational study ${ }^{74}$ wherein CRP and IL-6 levels from the femoral vein and coronary sinus were compared before curative ablation for AFL $(\mathrm{N}=59)$ and paroxysmal supraventricular tachycardia (SVT) $(\mathrm{N}=110)$. Followup levels were obtained at 1 and 6 months after ablation. Both CRP and IL-6 were significantly lower in the coronary sinus than in the periphery ( $P=0.0076$ and 0.0021 , respectively) in the AFL group. CRP has a significantly lower median of 47 days after AFL ablation (from a median of $6.28 \mathrm{mg} / \mathrm{L}$ to a median of $2.92 \mathrm{mg} / \mathrm{L} ; P=0.028$ ), and remained reduced at second follow-up. IL-6 decreased across three time points after AFL ablation $(P=0.002)$. Levels of each marker were similar in the coronary sinus and peripheral blood in the SVT group; and no reduction in inflammatory biomarkers was observed after SVT ablation. Because these levels significantly fall after ablation of AFL, the atrial tachyarrhythmia appears to be the cause (not the result) of the inflammation.

\section{Role of cytokines in postoperative atrial fibrillation}

Elevated IL-6 and hs-CRP levels in patients with postoperative AF suggest inflammatory components have a role in the pathogenesis of post operative AF (Table 5). ${ }^{8}$ In addition, higher concentrations of serum IL-8 in CABG patients with postoperative AF suggested a role for inflammation in the pathogenesis of AF after open heart surgery. Wu et al studied the relation of postoperative new AF and systemic inflammatory changes 


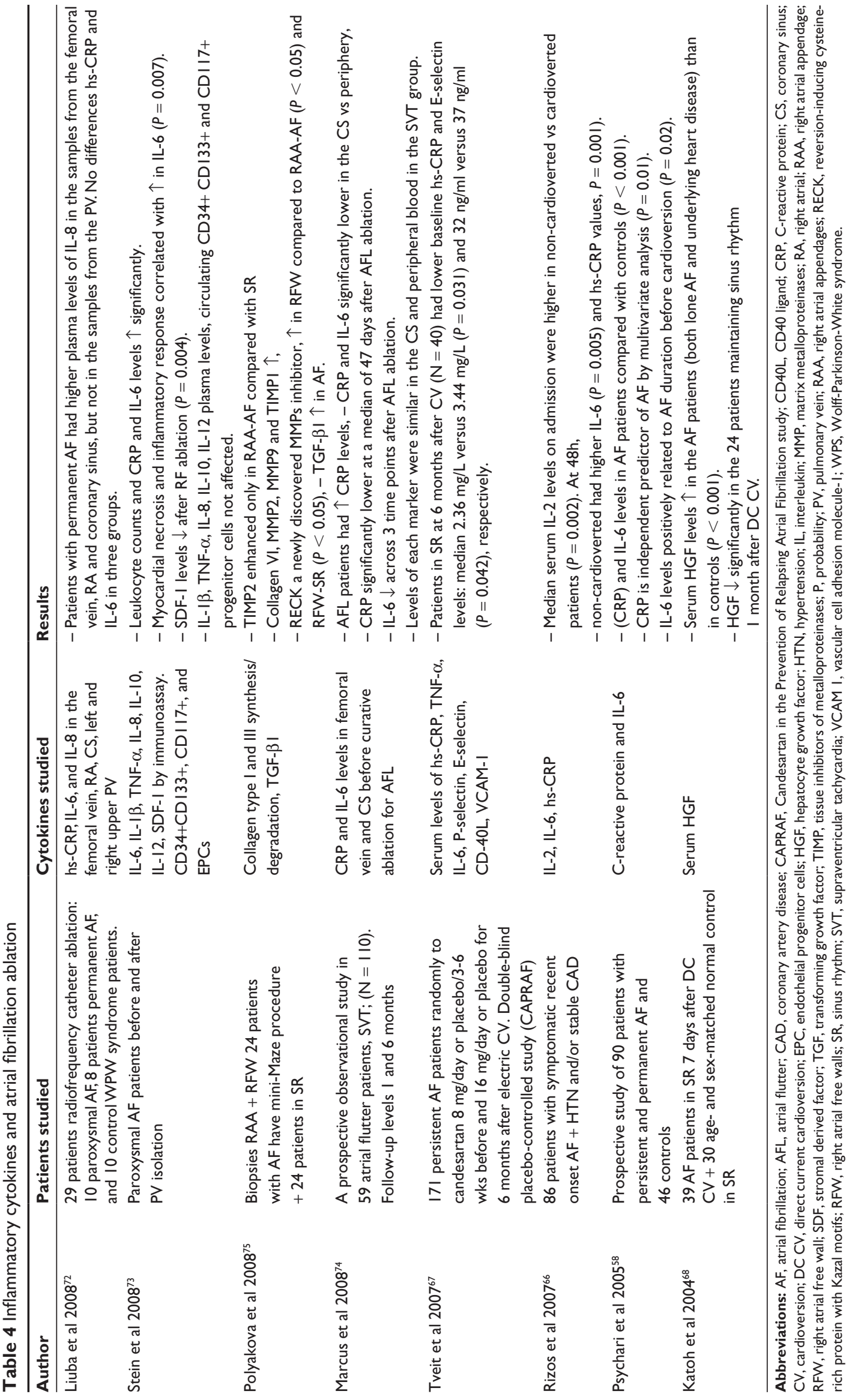


Table 5 Inflammatory cytokines in postoperative atrial fibrillation

\begin{tabular}{|c|c|c|c|}
\hline Author & Patients studied & Cytokines studied & Results \\
\hline Wu et al $2008^{9}$ & II 3 CABG patients & $\begin{array}{l}\text { IL-6, IL-8, and IL-I0, } \\
\text { I-day before operation } \\
\text { - POD2 }\end{array}$ & $\begin{array}{l}\text { - IL- } 6 \text { found in patients with and without AF. } \\
\text { - IL- } 8 \uparrow \text { at } 2 \text { hrs, PODI and POD } 2 \text { in postoperative } \\
\text { AF patients. Concentration of serum IL- } 10 \uparrow \text { on } \\
\text { PODI in postoperative AF patients. }\end{array}$ \\
\hline Gunaydin et al $2007^{106}$ & $\begin{array}{l}\text { In a prospective randomized study, } \\
\text { I } 20 \text { CABG patients }\end{array}$ & IL-2, C3a & $\begin{array}{l}\text { - Serum IL-2 levels significantly lower in the study } \\
\text { group. }(P<0.0 \text { I). } \\
\text { - C3a levels significant differences in leukofiltrated } \\
\text { group }(P<0.05)\end{array}$ \\
\hline Yared et al $2007^{15}$ & $\begin{array}{l}78 \text { patients undergoing combined } \\
\text { valve and } C A B G \text {, randomized } \\
\text { to receive either dexamethasone } \\
\text { or placebo }\end{array}$ & $\begin{array}{l}\text { IL-6, IL-8, IL-I0, TNF- } \alpha \text {, } \\
\text { ETI, complement (C4) } \\
\text { and CRP }\end{array}$ & $\begin{array}{l}\text { - No significant difference in the incidence of AF in } \\
\text { placebo }(41 \%) \text { vs DEX groups ( } 30 \%)(95 \% \mathrm{Cl}, \mathrm{I} \% \text {, } \\
34 \%, P=0.3 \mathrm{I}) \text {. } \\
\text { - DEX } \downarrow \text { least I postoperative level of IL-6, IL-8, } \\
\text { IL-I0, CRP, and exhaled NO. } \\
\text { - No affect on ET-I, C-4 levels. }\end{array}$ \\
\hline Amar et al $2005^{107}$ & $\begin{array}{l}\text { A prospective study in a tertiary care } \\
\text { cancer center of }|3| \text { patients (mean } \\
{[ \pm S D] \text { age, } 73 \pm 6 \text { years) who had }} \\
\text { major lung or esophageal resection }\end{array}$ & hs-CRP and IL-6 levels & $\begin{array}{l}\text { - CRP and IL-6 levels } \uparrow(P<0.00 \mathrm{I}) \text { in response to } \\
\text { surgery. } \\
\text { - Statin use associated with a 3-fold } \downarrow \text { in the odds of } \\
\text { developing AF (OR, 0.26; } 95 \% \mathrm{Cl}, 0.08-0.82 ; P=0.022)\end{array}$ \\
\hline
\end{tabular}

Abbreviations: AF, atrial fibrillation; CABG, coronary artery bypass graft; $\mathrm{Cl}$, confidence interval; CRP, C-reactive protein; hs-CRP, high-sensitivity $\mathrm{C}$-reactive protein; DEX, dexamethasone; ET, endothelin; NO, nitrous oxide; OR, odds ratio; POD, postoperative day; SD, standard deviation; TNF, tumor necrosis factor.

after CABG in a total of $113 \mathrm{CABG}$ patients using Holter data from 24-hour electrocardiography (1 day before the operation to postoperative day [POD] 2). Similar concentrations of serum IL-6 were found after surgery in patients with and without AF. The concentrations of serum IL-8 were significantly higher at 2 hours and on POD1 and POD2 in patients with postoperative AF. The concentration of serum IL-10 was significantly higher on POD1 in patients with postoperative AF. ${ }^{9}$

In a unique study, intraoperative biopsies from the right atrial appendages (RAA) and free walls (RFW) of 24 patients with AF undergoing a mini-Maze procedure; and 24 patients in SR; were investigated with qualitative and quantitative immunofluorescent and Western blot analyses. As compared with SR, all patients with AF exhibited dysregulations in collagen type I and type III synthesis/degradation. Tissue inhibitors of metalloproteinases (TIMP2) were significantly enhanced only in RAA-AF. As compared with SR, collagen VI, matrix metalloproteinases MMP2, MMP9 and TIMP1, were significantly increased, while TIMP3 and TIMP4 remained unchanged in all AF groups. Reversioninducing cysteine-rich protein with Kazal motifs (RECK), a newly discovered MMPs inhibitor, was elevated in RFW as compared to RAA-AF $(P<0.05)$ and RFW-SR $(P<0.05)$. The level of TGF- $\beta 1$ was higher in AF than SR. ${ }^{75}$

Atria of patients with permanent AF show evidence of calpain I activation that might contribute to structural remodeling and contractile dysfunction, without evidence of activation of tissue cytokines. Atrial fibrillation is accompanied by intracellular calcium overload. Goette et $\mathrm{al}^{76}$ assessed the role of calcium-dependent calpains and cytokines during AF. Atrial tissue samples from 32 patients [16 with chronic AF and 16 in sinus rhythm (SR)] undergoing open heart surgery looking for atrial expression of calpain I and II, calpastatin, troponin $\mathrm{T}(\mathrm{TnT})$, troponin C (TnC), and cytokines [IL-1, IL-2, IL-6, IL-8, IL-10, TGF- $\beta 1$, and TNF- $\alpha$ ] were determined. In these patients, expression of calpain I was increased during $\mathrm{AF}$ ( $461 \pm 201 \%$ vs $100 \pm 34 \%, P=0.05$ ), whereas the amounts of calpain II and calpastatin were unchanged. Total calpain enzymatic activity was more than doubled during $\mathrm{AF}(35.2 \pm 17.7 \mathrm{vs}$ $12.4 \pm 9.2$ units, $P<0.05)$. In contrast to TnC, $\mathrm{TnT}$ levels were reduced in fibrillating atria by $26 \%(P=0.05)$, corresponding to the myofilament disintegration seen by electron microscopy. Small amounts of only IL-2 and TGF- $\beta 1$ mRNA and protein were detected regardless of the underlying cardiac rhythm.

It has been suggested that inflammation can have a role in the development of atrial arrhythmias after cardiac surgery, and that a genetic predisposition to develop postoperative complications exists. In 110 primary isolated coronary artery bypass patients, the $-174 \mathrm{G} / \mathrm{C}$ IL- 6 promoter gene variant was determined. Plasma levels of IL-6, fibrinogen and CRP were determined preoperatively, 24, 48, and 72 hours after surgery and at discharge. Heart rate and rhythm were continuously monitored for the first 36 to 48 hours; daily 12-lead ECGs were performed thereafter until discharge. GG, CT, and CC genotypes were found in 62,38 , and 10 patients, respectively. Multivariate analysis (which included genotype, age, sex, and classical risk factors for AF) identified the GG genotype as the only independent predictor of postoperative AF. The 
latter occurred in $33.9 \%$ of GG versus $10.4 \%$ of non-GG patients (hazard ratio $3.25,95 \% \mathrm{CI} 1.23$ to 8.62 ). AF patients had higher blood levels of IL- 6 and fibrinogen after surgery ( $P=0.001$ for difference between the area under the curve). The $-174 \mathrm{G} / \mathrm{C}$ IL-6 promoter gene variant appears to modulate the inflammatory response to surgery and to influence the development of postoperative AF. These data suggest an inflammatory component of postoperative atrial arrhythmias and a genetic predisposition to this complication.

The analysis in this study is a post-hoc comparison of data collected in a prospective randomized investigation, and the relatively small number of patients enrolled limits the statistical power of the study. The failure to identify as predictors of postoperative AF some variables that have been linked with this arrhythmia in other series can in fact be an expression of the reduced statistical power of this series. However, the fact that, despite the reduced power, the authors were able to clearly define a relationship between the IL-6 gene promoter polymorphism and the occurrence of postoperative AF may reflect the important role of this polymorphism in the determination of atrial arrhythmias after coronary artery surgery. A further limitation is that continuous telemetry was used only for the first 72 hours after surgery, and from this time on patients were submitted to surface ECG every day, and in case of clinical suspicion of arrhythmia. This methodology may have resulted in missing some episodes of transient asymptomatic atrial arrhythmia. However, it seems less likely that these episodes can have a significant incidence in patients who did not develop persistent or symptomatic atrial arrhythmia during their entire postoperative course (and that have been classified in the "without atrial arrhythmias" group in the univariate and multivariate analysis), and thus, their confounding effect is likely to be minimal. ${ }^{77}$

\section{Diagnosis and therapeutics Prognostic value of cytokines in atrial fibrillation}

Among AF patients, cytokines can have a prognostic significance; IL-6 levels, but not prothrombin fragment $1+2$, correlates with a point-based score for stroke risk in AF, even after oral anticogulation. ${ }^{78}$ High plasma IL-6 levels were an independent predictor of stroke and the composite end point of stroke or death. ${ }^{79}$

CRP was positively correlated to stroke risk and related to stroke risk factors and prognosis (mortality, vascular events). Soluble CD40 ligand levels were lowest in those at moderate to high risk of stroke and not related to prognosis. Data from 880 subjects with AF receiving aspirin $325 \mathrm{mg} / \mathrm{d}$ (alone or combined with fixed inefficacious doses of warfarin) from the Stroke Prevention in Atrial Fibrillation (SPAF) III clinical trial were analyzed. Using SPAF III stroke risk stratification criteria, those with moderate to high risk had the highest levels of CRP (Kruskal Wallis test, $P<0.001$ ), but those with the highest risk had the lowest levels of soluble CD40 ligand $(P=0.01)$. Similarly, CRP levels increased in a positive fashion with increasing stroke risk as estimated by the $\mathrm{CHADS}_{2}$ risk score and NICE risk stratification criteria, whereas soluble CD40 ligand levels were negatively associated with stroke risk. CRP levels were higher among patients with high body mass index, diabetes, hypertension, ischemic heart disease, peripheral vascular disease, or recent heart failure, but not those with thromboembolism. All-cause mortality (log rank test, $P=0.001)$, and vascular events $(P=0.05)$, but not stroke, were more common in patients with high CRP levels. Soluble CD40 ligand levels were not related to stroke, vascular events, or all-cause mortality. ${ }^{80}$ Another study suggested that plasma sCD40L may prospectively predict stroke in patients with AF. Levels of soluble CD40 ligand (sCD40L) could predict subsequent thromboembolic events in patients with nonvalvular AF (NVAF). In forty-four consecutive outpatients (mean age: $58 \pm 6$ years, 20 male) with chronic NVAF who were not receiving aspirin and had no thrombus or spontaneous echo contrast (SEC) on left atrium or left atrial appendage, $\mathrm{SCD} 40 \mathrm{~L}$ was significantly higher in patients with left atrial spontaneous echo contrast (LASEC) $(0.41 \pm 0.05$ vs $0.16 \pm 0.04 \mathrm{ng} / \mathrm{mL}, P=0.02)$ and embolic events $(0.74 \pm 0.05$ vs $0.19 \pm 0.03 \mathrm{ng} / \mathrm{mL}, P=0.001)$ than in those without. $\mathrm{sCD} 40 \mathrm{~L}$ levels were significantly related to the LASEC grade $(\mathrm{R}=0.377, P=0.02)$. In multivariable analysis, independent variables for SEC or thrombus formation were LA diameter and SCD40L levels, whereas the duration of AF, independent variables for cerebrovascular events. ${ }^{80}$ Ferro et al found that enhanced soluble CD40L level is a predictor of vascular events in patients with nonvalvular AF, thus suggesting that enhanced platelet activation may play a role in its clinical progression. In 231 patients (177 [77\%] had permanent or persistent AF, and 54 [23\%] had paroxysmal AF) followed for a mean period of $27.8 \pm$ 8.8 months, patients with sCD40L above the median were 4.63 times more likely to experience a vascular event $(95 \%$ CI: 1.92-11.20) compared to patients with levels below the median. $^{81}$

\section{Link between inflammatory cytokines, adhesion molecules and risk of thromboembolism}

AF confers a hypercoagulable state, even in the absence of underlying heart disease. Abnormalities of hemostasis, 
fibrinolysis, endothelium, and platelets have all been described in AF, which may increase the risk of stroke and thromboembolism. ${ }^{55,66,70,82,83}$ Although there appears to be a link between inflammation and AF, one of the key questions is whether the observed inflammation in AF increases the risk of thromboembolism as has been demonstrated for atherosclerotic models. Plasma levels of CRP $(P=0.03)$ and soluble P-selectin $(P=0.04)$ and hematocrit $(P=0.004)$ were higher among patients with long-term AF receiving warfarin with dense SEC than among those without SEC on transesophageal echocardiography. ${ }^{85}$ The high levels of $\beta$ TG and PF4 in patients with AF may be one explanation for the high incidence of thromboembolism in AF patients with and without valvular heart disease. ${ }^{84}$

Conway et $\mathrm{a}^{85}$ were the first to confirm this putative link between inflammation and complications of AF. In a small pilot study, they showed that elevated IL-6 levels were an independent predictor of the composite of stroke or death among a cohort of 77 high-risk AF patients. This observation was complemented by data from Thambidorai et al, ${ }^{86}$ which showed that among 104 patients with AF, transesophageal echocardiography-based risk factors for stroke were greater for patients with elevated hs-CRP compared with those with normal levels. Hence, there appears to be an established link between inflammation, AF, and thrombosis.

Markers of thrombin generation and platelet activation are often elevated in patients with nonvalvular AF, but it is unclear whether such markers usefully predict stroke. Feinberg et $\mathrm{al}^{87}$ assessed the relationship between prothrombin fragment F1.2 (F1.2), $\beta$ TG, fibrinogen, and the factor V Leiden mutation and stroke, in AF. Specimens were obtained from 1531 participants in the SPAF III study. The results were correlated with patient characteristics, antithrombotic therapy, and subsequent thromboembolism (ischemic stroke and systemic embolism) by multivariate analysis. Increased F1.2 levels were associated with age $(P=0.001)$, female sex $(P=0.001)$, systolic blood pressure $(P=0.006)$, and heart failure $(P=0.001)$. F1.2 were not affected by aspirin use and were not associated with thromboembolism after adjustment for age $(P=0.18)$. $\beta$ TG levels were higher with advanced age $(P=0.006), \mathrm{CAD}(P=0.05)$, carotid disease $(P=0.005)$, and heart failure $(P=0.001)$, lower in regular alcohol users $(P=0.05)$, and not significantly associated with thromboembolism. Fibrinogen levels were not significantly related to thromboembolism but were associated with elevated $\beta$ TG levels $(P=0.001)$. The factor V Leiden muta- tion was not associated with thromboembolism (relative risk 0.5, 95\% CI 0.1-3.8). Elevated F1.2 levels were associated with clinical risk factors for stroke in AF, whereas increased $\beta$ TG levels were linked to manifestations of atherosclerosis. In this large cohort of patients with AF who were receiving aspirin, F1.2, $\beta$ TG, fibrinogen, and factor V Leiden were not independent, clinically useful predictors of stroke.

Another relatively small study ${ }^{88}$ enrolled a total of 40 patients, 20 patients with persistent AF and 20 matched patients with SR quantified platelet surface expression of CD40/CD40L, serum levels of intercellular adhesion molecule-1 (ICAM), vascular adhesion molecule-1 (VCAM), hs-CRP, and monocyte chemoattractant protein-1 (MCP-1). Using fluorescence-activated cell sorting analysis, baseline CD40 expression (antibody binding capacity [ABC]) was increased in patients with AF (AF: $777668.46 \mathrm{ABC}$ vs SR: 775367.32 ABC; $P<0.05$ ), whereas CD40L expression was not different between the two groups. In contrast to the effect of adenosine diphosphate, ex vivo stimulation with thrombin receptor activating peptide (TRAP) increased CD40 and CD40L expression in both groups. MCP-1, hs-CRP, ICAM, and VCAM levels were significantly increased in patients with AF, reaching highest levels in patients with atrial thrombi. VCAM and MCP-1 were independent predictors for atrial thrombi ( $P<0.05$, using multivariate analysis). In contrast to declining levels of hs-CRP, levels of ICAM, VCAM, MCP-1, and platelet CD40 expression remained elevated 5 weeks after successful electrical direct current cardioversion. In addition to hs-CRP, MCP-1 and VCAM may serve as new biomarkers, which may help to identify patients with an increased risk for thromboembolic events. AF is not an absolute prerequisite for the development of such prothrombogenic alterations at the atrial endocardium, because it was demonstrated that pressure overload ("stretch") per se causes increased expression of various endocardial proteins. ${ }^{89}$ Therefore, in many patients with AF it has to be considered that the development of the arrhythmia might be a secondary phenomenon related to preexisting structural and thereby prothrombogenic alterations of the atrial myocardium and endocardium ("endocardial remodeling"). Thus, in some patients a prothrombogenic milieu persists or is imminent, whereas the presence of AF on the surface ECG may serve only as a marker for such alterations. This may help to explain the finding that VCAM and MCP-1 levels remained elevated for weeks after successful cardioversion of AF, because the underlying structural abnormalities of the atria are not instantaneously normalized by restoration of sinus rhythm. 
Of note, MCP-1 and VCAM levels are independent predictors for atrial thrombi, which suggest a clinical importance for this finding. MCP-1 and VCAM appear as biomarkers, which may help identify patients with an increased risk for thromboembolic events.

Plasma levels of sCD40L are elevated in patients with AF, and are related to levels of VEGF, angiopoietin (Ang)-2, and tissue factor (TF). This interaction among platelets, angiogenic markers, and TF may play a role in the generation of the prothrombotic state associated with AF. In 59 patients with chronic AF measuring plasma levels of soluble CD40 ligand (sCD40L [an index of platelet activation]) and $\mathrm{TF}$ [an index of coagulation], as well as the angiogenic factors, VEGF, angiopoietin (Ang-1, and Ang-2) by enzyme-linked immunosorbent assay, AF patients had significantly higher levels of $\mathrm{sCD} 40 \mathrm{~L}(P=0.038)$, VEGF $(P=0.023)$, and Ang-2 $(P<0.001)$, but not Ang-1 $(P=0.363)$, compared to control subjects. In nonanticoagulated AF patients $(\mathrm{N}=28)$, TF levels were also higher $(P=0.043)$, in addition to high sCD40L, VEGF, and Ang-2, compared to control subjects. Among AF patients, sCD40L levels correlated strongly with levels of VEGF $(\mathrm{R}=0.919 ; P<0.001)$ and Ang-2 $(\mathrm{R}=0.546 ; P=0.002)$. VEGF levels were significantly correlated with levels of Ang-2 $(\mathrm{R}=0.490 ; P<0.001)$ and $\mathrm{TF}$ ( $\mathrm{R}=0.298 ; P=0.044)$. In multivariate regression analysis, $\mathrm{sCD} 40 \mathrm{~L}$ levels were independently associated with levels of $\operatorname{VEGF}(P=0.003)$ and Ang-2 $(P=0.005) .{ }^{90}$

Patients with chronic AF have high TF levels, in keeping with the prothrombotic state associated with this arrhythmia. The relationships between TF and VEGF and its receptor sFlt-1 in AF suggest a possible role for VEGF in the hypercoagulable state found in AF, as seen in malignancy and atherosclerosis. Chung et al ${ }^{91}$ studied 25 patients with AF (20 men; mean \pm SD age, $62 \pm 13$ years) who were compared with two control groups in sinus rhythm: 30 healthy control subjects (17 men; mean age, $60 \pm 9$ years) and 35 patient control subjects with CAD (CAD; 27 men; mean age, $60 \pm 12$ years). Plasma levels of TF, VEGF, and the VEGF receptor sFlt-1 were measured by enzyme-linked immunosorbent assay. VEGF, sFlt-1, and TF were significantly different between the three groups, with abnormal levels in $\mathrm{AF}$ and $\mathrm{CAD}$ patients compared with control subjects ( $P<0.001, P=0.022$, and $P=0.008$, respectively). Among the AF patients, TF levels were significantly correlated with VEGF $(P<0.001)$ and sFlt $(P=0.006)$ levels. Only $\mathrm{TF}$ and VEGF levels were significantly correlated in CAD patients $(P<0.02)$. There were no significant correlations among the healthy control subjects. This study is limited by its cross-sectional design but was adequately powered to undertake the main analyses in relation to patients with AF. In this study AF patients were also taking warfarin, but there is no evidence to suggest that warfarin influences the levels of the indexes measured. Furthermore, a cross-sectional design of this study helps only to explore associations; no causality is implied because only a prospective cohort study with large numbers of subjects with AF can confirm the natural history of the indexes measured in the short, medium, and long term in relation to interventions (cardioversion, introduction of antithrombotic therapy, etc), as well as morbidity and mortality.

Increased plasma IL-6, CRP, and plasma viscosity support the case for the existence of an inflammatory state among "typical" populations with chronic AF. These markers of inflammation are related to indices of the prothrombotic state and may be related to the clinical variables of the patients (underlying vascular disease and co-morbidities), rather than simply to the presence of AF itself). ${ }^{56}$ FXIII Val34Leu polymorphism was independently associated with IL-6 levels in AF. The Leu34 allele may potentially influence the prothrombotic state in these patients by modulating the inflammatory state. ${ }^{92}$

The endocardial surface could be considered as part of the systemic endothelium, which could be a source of E-selectin, but the data differentiating between the two in relation to E-selectin are limited. However, the expression of E-selectin in endocardium has been studied in relation to human cardiac allograft rejection, but these studies demonstrated a little or no expression of E-selectin in endocardium specimens. ${ }^{93-95}$ Kamath et al studied 122 patients (mean age $\pm \mathrm{SD}=71 \pm 9$ years; 65 men) with chronic AF of 6 weeks' duration: 34 were not on antithrombotic therapy, 30 were taking aspirin (75 to $300 \mathrm{mg} / \mathrm{d}$ ), and 58 were fully anticoagulated with warfarin. $\mathrm{P}$-selectin per platelet (pP-selectin) was compared with soluble P-selectin (sP-selectin) and plasma $\beta T G$ levels (enzyme-linked immunosorbent assay). Results were compared with those of 23 healthy controls (mean age $\pm \mathrm{SD}=74 \pm$ years; 7 men) in sinus rhythm. pP-selectin was significantly lower in AF patients on no antithrombotic therapy $(P=0.03)$ than in healthy controls, but sP-selectin and $\beta$ TG levels were not significantly different and did not differ in patients taking aspirin or warfarin. However, pPselectin was lower in patients with AF on aspirin than in those on warfarin $(P=0.05)$. pP-selectin/sP-selectin correlated significantly in healthy controls $(\mathrm{R}=0.47, P=0.03)$ 
but inversely ( $\mathrm{R}=0.43, P=0.03)$ in AF patients on no antithrombotic therapy. The results from this study suggest that even though P-selectin is expressed on the surface of platelets in AF, the absolute pP-selectin level is low. Furthermore, whether the absolute amount of P-selectin within a platelet reflects platelet activation is unclear. The finding of lower pP-selectin in AF than in healthy controls could potentially be explained in two ways. ${ }^{96}$ First, activated platelets in AF result in the fusion of granules with the platelet surface, followed by degranulation. This results in the expression of P-selectin on the platelet surface and possible release into the plasma. While the amount of P-selectin depleted may be great enough to result in a significant decrease in pP-selectin, it may not be high enough to make a significant difference to the larger plasma reserve of sP-selectin. This is further supported by the finding that $\mathrm{pP}$-selectin showed a negative significant correlation with $\mathrm{sP}$-selectin in patients with AF and not in healthy controls. Therefore, after platelet activation, P-selectin may be depleted in the platelets and may increase in the plasma. Second, it is theoretically possible that P-selectin, which is expressed on the surface of the platelet on activation, changes its configuration and is detected by the specific antibody during flow cytometry. Since the ELISA was used to detect pP-selectin, it is possible that the antibody has detected only granule P-selectin, not recognizing the membrane P-selectin. This concept is also supported by Semenov et al who demonstrated that the polyclonal antibody they used in their study to detect sPselectin in a platelet had lower reactivity toward membrane P-selectin. Furthermore, $90 \%$ of the P-selectin in the lysate is accounted for by the membrane P-selectin and $10 \%$ by the sP-selectin in the platelet granules membrane. ${ }^{97}$

Aspirin has previously been shown to have no significant effect on sP-selectin levels. ${ }^{98-100}$ Aspirin appears to decrease the amount of $\mathrm{pP}$-selectin in patients with $\mathrm{AF}$ in comparison to those on adjusted-dose warfarin. Although previous studies have suggested a cyclooxygenase-independent mechanism for the production of $\mathrm{P}$-selectin, whether $\mathrm{pP}$-selectin is a product of pathways involving cyclooxygenase remains to be seen.

Roldán et al $^{101}$ studied 191 consecutive patients (98 male; mean age $72.3 \pm 9.2$ years) with chronic nonrheumatic AF who were not on anticoagulant therapy. Plasma IL-6, endothelial activation (soluble E-selectin [sEsel]) and prothrombin fragment $1+2(\mathrm{~F} 1+2)$ were measured by ELISA. Research indices were compared to 74 controls in sinus rhythm matched for age and sex. In 43 patients with AF, the effects of introducing anticoagulation (INR
2.0-3.0) were also studied. Patients with AF had elevated levels of F1 $+2(P<0.001)$ and IL-6 $(P=0.045)$, but not sEsel. There was no significant correlation between $\mathrm{F} 1+2$ and IL-6. In multivariate analysis, only F1+2 levels were independently associated with the presence of AF $(P=0.001)$. After oral anticoagulation, plasma levels of F1 +2 and sEsel were significantly decreased (both $P<0.01)$. High levels of IL-6 in AF suggest an inflammatory state, which appears to be more related to clinical variables of the patients, rather than to the presence of AF per se. There was no association of inflammation with sEsel or the presence of abnormal thrombogenesis (high F1 + 2 levels) in AF. Moreover, no changes in IL-6 levels were found despite the reduction of the other markers by oral anticoagulant therapy. This study, which investigated a fairly large cohort of patients with AF, who had documented AF of $>4$ weeks duration, is limited by its cross-sectional design, which only allows exploring associations, and no causality is implied, as only a prospective cohort study with large numbers of subjects with AF can confirm the natural history of the indices measured in the short-, medium-, and long-term. Indeed, IL-6 is a key inflammatory cytokine, and is normally present in low concentrations (but increases with infection, trauma, stress and age, etc); thus, an ability to determine the independent relationship between IL- 6 and AF would certainly require further longitudinal studies, as well as prolonged periods of 'exposure' to the particular disease state.

\section{Therapeutic implications}

Several animal studies have shown the relation between inflammatory cytokines and atrial tachyarrythmias including AF. Rabbits subjected to ventricular tachypacing at 380 to 400 beats per minute (bpm) for 4 weeks in the absence and presence of treatment with pioglitazone, candesartan, and combined pioglitazone and candesartan were assessed by electrophysiologic study ${ }^{102}$ together with atrial fibrosis measurements, and cytokine expression analyses. Both pioglitazone and candesartan reduced TGF- $\beta 1$, TNF- $\alpha$, and activated extracellular signal-regulated kinase expression similarly, but neither affected p38-kinase nor c-Jun N-terminal kinase activation. The effects of combined pioglitazone and candesartan therapy were not significantly different from the effects of pioglitazone or candesartan alone. Pioglitazone reduced the duration of AF $(3.5 \pm 0.2$ seconds, $P<0.05)$ and attenuated atrial structural remodeling, with significant reductions in interatrial activation time ( $50 \pm 2 \mathrm{~ms}$ vs $41 \pm 2 \mathrm{~ms}, P<0.05)$, and atrial fibro- 
sis $(16.8 \% \pm 0.8 \%$ vs $10.9 \% \pm 0.7 \%, P<0.05$; control $1.6 \% \pm 0.2 \%$ ); effects comparable to those of candesartan (duration of AF: $3.0 \pm 0.2$ seconds; activation time $44 \pm 2$ ms; fibrosis: $9.4 \% \pm 0.6 \%$ ).

Chronic AF acutely upregulates CD40 expression as well as platelet adhesion to the endocardium. Simvastatin is effective in modulating this expression, thus it may potentially contribute to reduction of the risk of intraatrial thrombus formation. This issue has been explored in experiments on right atrial segments obtained before the onset of cardiopulmonary bypass, in either presence or absence of 5 micrM simvastatin. AF was associated with a significant increase of endocardial CD40 expression $(293.1 \pm 55.1 \mathrm{pg} / \mathrm{mL}$ vs $230.9 \pm$ $53.3 \mathrm{pg} / \mathrm{mL} ; P<0.01$ ), and platelet-endocardial adhesion compared with sinus rhythm ( $10.8 \pm 2.2$ vs $5.2 \pm 1.3$ platelet CD41 AU; $P<0.01$ ). At immunofluorescence, about $62 \%$ of fibrillating endocardium was covered by platelets, compared with $12 \%$ with sinus rhythm. Addition of simvastatin significantly reduced CD40 expression as well as platelet adhesion to fibrillating atria. Its efficacy was not reversed by the addition of mevalonic acid. ${ }^{103}$

The observed inflammatory response is consistent with histopathologic information on ablation-induced inflammatory activation and is supposed to contribute to the phenomenon of early AF recurrence after ablation. ${ }^{44,82}$ Although it is not yet known whether inflammation acts as an initiator or is just a consequence of $\mathrm{AF}$, there is evidence that CRPlowering therapies could prevent $\mathrm{AF}^{54,62}$ Statins as well as angiotensin-converting enzyme inhibitors (ACE-Is) and angiotensin receptor blockers (ARBs) have the potential to modulate inflammatory pathways and could therefore reduce the susceptibility to AF after ablation in general, and attenuate the acute inflammatory response in the early post ablation period.

Furthermore, CRP-lowering with atorvastatin appears to be effective in eliminating PAF during daily life in a significant proportion of patients. In a prospective study of 80 patients with proven PAF, 40 patients were randomized to placebo (placebo group) and 40 to atorvastatin (treatment group). Plasma CRP levels and ambulatory monitoring were repeated after 4 to 6 months of therapy. The two groups were comparable with respect to baseline characteristics, baseline number of episodes of PAF, and baseline plasma CRP levels. The treatment group had lower median CRP levels and exhibited a highly significant reduction in PAF $(P<0.001)$. Paroxysmal AF completely resolved in $26(65 \%)$ of 40 patients in the treatment group versus four $(10 \%)$ of 40 in the placebo group. By logistic regression, treatment with atorvastatin was an independent predictor of PAF resolution. ${ }^{63}$

Treatment of CHF canines with the antifibrotic drug pirfenidone (PFD) resulted in an attenuation of arrhythmogenic left atrial remodeling, with a significant reduction in left atrial conduction heterogeneity index, left atrial fibrosis and AF duration. Immunoblotting studies demonstrated the drug's effects on multiple cytokines, including a reduction in TGF-1 expression. ${ }^{104}$ In transgenic mice with targeted overexpression of TNF in the cardiac compartment, sustained inflammatory signaling contributed to atrial structural remodeling and down regulation of connexin 40 that was associated with an increased prevalence of atrial arrhythmias. ${ }^{105}$

Leukofiltration and coating significantly reduce the incidence, ventricular rate, and duration of $\mathrm{AF}$ after $\mathrm{CABG}$ via modulation of systemic inflammatory response and platelet preservation in high risk groups. In a prospective randomized study, 120 patients undergoing CABG were allocated into two groups $(\mathrm{N}=60)$. Group 1 - polymethoxyethylacry late-coated circuits + leukocyte filters (Terumo, USA); Group 2 - control: uncoated circuits (Terumo, USA). Each group was further divided into three subgroups $(\mathrm{N}=20)$ with respect to low (Euroscore 0-2), medium (3-5), and high (6+) risk patients, serum IL-2 levels were significantly lower in the study group at T4 and T5 $(P<0.01)$. C3a levels showed significant differences in the leukofiltrated group at $\mathrm{T} 4$ and T5 $(P<0.05) .{ }^{106}$

CRP and IL-6 levels increased significantly $(P<0.001)$ in response to surgery (major lung or esophageal resection) $)^{107}$ and dexamethasone did not affect the incidence of $\mathrm{AF}$ in patients undergoing combined $\mathrm{CABG}$ and valve surgery. ${ }^{108}$ However, it did modulate the release of several inflammatory and acute-phase response mediators that are associated with adverse outcomes. In this study, 78 adult patients undergoing combined valve and $\mathrm{CABG}$ surgery were randomized to receive either dexamethasone or placebo, No significant difference in the incidence of postoperative AF was found between the placebo (41\%) and dexamethasone groups $(30 \%)(95 \%$ confidence interval $[-11 \%, 34 \%] ; P=0.31)$. Dexamethasone significantly reduced at least 1 postoperative level of IL-6, IL-8, IL-10, CRP, and exhaled nitrous oxide. Dexamethasone did not affect endothelin-1 or C-4 levels. On the other hand the preoperative use of statins was associated with a protective effect against postoperative AF, independent of CRP levels. ${ }^{107}$ In contrast to AF in the general population, early markers of inflammation did not predict the postoperative occurrence of AF. 


\section{Future perspectives}

The future will witness increasing interest in finding reliable methods of testing the prognostic utility of cytokines in different types of AF. Several large noninvasive and invasive studies are needed to determine the predictive value of cytokines as a potential predictor of $\mathrm{AF}$ and the associated risk of thromboembolism. Establishing cytokines as prognostically useful and potentially as therapeutic targets may change our understanding of $\mathrm{AF}$ and revolutionize our treatment strategy for one of the most difficult sustained arrhythmias encountered in clinical practice.

\section{Disclosure}

The authors report no conflicts of interest in this work.

\section{References}

1. Fuster V, Ryden LE, Asinger RW, et al. American College of Cardiology (ACC)/American Heart Association (AHA)/European Society of Cardiology (ESC) guidelines for the management of patients with atrial fibrillation: executive summary report of the ACC/AHA Task Force on practice guidelines and the ESC Committee for practice guidelines and policy conferences (committee to develop guidelines for the management of patients with atrial fibrillation) developed in collaboration with the North American Society of Pacing and Electrophysiology. Circulation. 2001;104:2118-2150.

2. Go AS, Hylek EM, Phillips KA, et al. Prevalence of diagnosed atrial fibrillation in adults: national implications for rhythm management and stroke prevention: the anticoagulation and risk factors in atrial fibrillation (ATRIA) study. JAMA. 2001;285:2370-2375.

3. Benjamin EJ, Wolf PA, D'Agostino RB, et al. Impact of atrial fibrillation on the risk of death: the Framingham Heart Study. Circulation. 1998;98:946-952.

4. Gronefeld GC, Lilienthal J, Kuck KH, et al. Pharmacological Intervention in Atrial Fibrillation (PIAF) Study Investigators. Impact of rate versus rhythm control on quality of life in patients with persistent atrial fibrillation: results from a prospective randomized study. Eur Heart $J$. 2003;24:1430-1436.

5. Saxena R, Lewis S, Berge E, et al. Risk of early death and recurrent stroke and effect of heparin in 3169 patients with acute ischemic stroke and atrial fibrillation in the International Stroke Trial. Stroke. 2001;32: 2333-2337.

6. Spach MS, Dolber PC. Relating extracellular potentials and their derivatives to anisotropic propagation at a microscopic level in human cardiac muscle: evidence for electrical uncoupling of side-to-side fiber connections with increasing age. Cardiovasc Res. 1986;58:356-371.

7. Fujiki A, Sakamoto T, Nishida K, et al. Relation of Interleukin-6 and C-reactive protein levels to sinus maintenance after pharmacological cardioversion in persistent atrial fibrillation. J Cardiovasc Pharmacol. 2007;50(3):264-266.

8. Ucar HI, Tok M, Atalar E, et al. Predictive significance of plasma levels of Interleukin-6 and high-sensitivity C-reactive protein in atrial fibrillation after coronary artery bypass surgery. Heart Surg Forum. 2007;10(2):E131-E135.

9. Wu ZK, Laurikka J, Vikman S, et al. High postoperative Interleukin-8 levels related to atrial fibrillation in patients undergoing coronary artery bypass surgery. World J Surg. 2008;32:2643-2649.

10. Sjoholm A, Nystrom T. Endothelial inflammation in insulin resistance. Lancet. 2005;365:610-612.

11. Nadar S, Blann AD, Lip GY. Endothelial dysfunction: methods of assessment and application to hypertension. Curr Pharm Des. 2004;10: 3591-3605.
12. Boos CJ, Lip GYH. The role of inflammation in atrial fibrillation. Int J Clin Pract. 2005;59:870-872.

13. Bruins P, te Velthuis H, Yazdanbakhsh AP, et al. Activation of the complement system during and after cardiopulmonary bypass surgery: post surgery activation involves C-reactive protein and is associated with postoperative arrhythmia. Circulation. 1997;96: 3542-3548

14. Anderson JL, Allen Maycock CA, et al. Frequency of elevation of C-reactive protein in atrial fibrillation. Am J Cardiol. 2004;94: $1255-1259$.

15. Yared JP, Starr NJ, Torres FK, et al. Effects of single dose, post induction dexamethasone on recovery after cardiac surgery. Ann Thorac Surg. 2000;69:1420-1424.

16. Schotten U, Ausma J, Stellbrink C, et al. Cellular mechanisms of depressed atrial contractility in patients with chronic atrial fibrillation. Circulation. 2001;103:691-698.

17. Kucera JP, Rudy Y. Mechanistic insights into very slow conduction in branching cardiac tissue: a model study. Circ Res. 2001;89: 799-806.

18. Kostin S, Klein G, Szalay Z, et al. Structural correlate of atrial fibrillation in human patients. Cardiovasc Res. 2002;54:361-379.

19. Boldt A, Wetzel U, Lauschke J, et al. Fibrosis in left atrial tissue of patients with atrial fibrillation with and without underlying mitral valve disease. Heart. 2004;90:400-405.

20. Hadi HA, Mahmeed WA, Suwaidi JA, et al. Pleiotropic effects of statins in atrial fibrillation patients: the evidence. Vasc Health Risk Manag. 2009;5(3):533-551.

21. Frustaci A, Chimenti C, Bellocci F, et al. Histological substrate of atrial biopsies in patients with lone atrial fibrillation. Circulation. 1997;96:1180-1184.

22. Tsai CT, Lai LP, Kuo KT, et al. Angiotensin II activates signal transducer and activators of transcription 3 via Rac1 in atrial myocytes and fibroblasts: implication for the therapeutic effect of statin in atrial structural remodeling. Circulation. 2008b;117(3):344-355.

23. Neuman RB, Bloom HL, Shukrullah I, et al. Oxidative stress markers are associated with persistent atrial fibrillation. Clin Chem. 2007; 53(9):1652-1657.

24. Tang RB, Dong JZ, Liu XP, et al. Inflammation and atrial fibrillation: is Chlamydia pneumoniae a candidate pathogen of atrial fibrillation? Med Hypotheses. 2006;67(3):462-466.

25. Nakamura Y, Nakamura K, Fukushima-Kusano K, et al. Tissue factor expression in atrial endothelia associated with nonvalvular atrial fibrillation: possible involvement in intracardiac thrombogenesis. Thromb Res. 2003;111(3):137-142.

26. Anné W, Willems R, Roskams T, et al. Matrix metalloproteinases and atrial remodeling in patients with mitral valve disease and atrial fibrillation. Cardiovasc Res. 2005;67(4):655-666.

27. Boos CJ, Lip GY, Jilma B. Endotoxemia, inflammation, and atrial fibrillation. Am J Cardiol. 2007;100(6):986-988.

28. Guazzi M, Belletti S, Bianco E, et al. Endothelial dysfunction and exercise performance in lone atrial fibrillation or associated with hypertension or diabetes: different results with cardioversion. Am J Physiol. 2006;291:H921-H928.

29. Kim YM, Guzik TJ, Zhang YH, et al. A myocardial Nox2 containing NAD(P)H oxidase contributes to oxidative stress in human atrial fibrillation. Circ Res. 2005;97:629-636.

30. Choudhary G, Dudley SC Jr. Heart failure, oxidative stress, and ion channel modulation. Congest Heart Fail. 2002;8:148-155.

31. Touyz RM, Schiffrin EL. Reactive oxygen species in vascular biology: implications in hypertension. Histochem Cell Biol. 2004;122: 339-352.

32. Adams JD Jr, Lauterburg BH, Mitchell JR. Plasma glutathione and glutathione disulfide in the rat: regulation and response to oxidative stress. J Pharmacol Exp Ther. 1983;227:749-754.

33. Seko Y, Seko Y, Takahashi N, et al. Pulsatile stretch stimulates vascular endothelial growth factor (VEGF) secretion by cultured rat cardiac myocytes. Biochem Biophys Res Commun. 1999;254:462-465. 
34. Seko Y, Seko Y, Takahashi N, et al. Pulsatile stretch activates mitogen activated protein kinase (MAPK) family members and focal adhesion kinase (p125FAK) in cultured rat cardiac myocytes. Biochem Biophys Res Commun. 1999;259:8-14.

35. Lee SH, Chen YC, Chen YJ, et al. Tumor necrosis factor- $\alpha$ alters calcium handling and increases arrhythmogenesis of pulmonary vein cardiomyocytes. Life Sci. 2007;80(19):1806-1815.

36. Seko Y, Imai Y, Suzuki S, et al. Serum levels of vascular endothelial growth factor in patients with acute myocardial infarction undergoing reperfusion therapy. Clin Sci. 1997;92:453-454.

37. Blann AD, Choudhury A, Freestone B, et al. Soluble CD40 ligand and atrial fibrillation: Relationship to platelet activation, and endothelial damage/dysfunction. Int J Cardiol. 2008;127(1):135-137.

38. Choudhury A, Chung I, Panja N, et al. Soluble CD40 ligand, platelet surface CD40 ligand, and total platelet CD40 ligand in atrial fibrillation. Chest. 2008;134:574-581.

39. Marcus GM, Whooley MA, Glidden DV, et al. Interleukin-6 and atrial fibrillation in patients with coronary artery disease: data from the Heart and Soul Study. Am Heart J. 2008;155(2):303-309.

40. Dudley SC Jr, Hoch NE, McCann LA, et al. Atrial fibrillation increases production of superoxide by the left atrium and left atrial appendage: role of the NADPH and xanthine oxidases. Circulation. 2005; 112:1266-1273.

41. Sata N, Hamada N, Horinouchi T, et al. C-reactive protein and atrial fibrillation: is inflammation a consequence or a cause of atrial fibrillation? Jpn Heart J. 2004;45:441-445.

42. Lamirault G, Gaborit N, Le Meur N, et al. Gene expression profile associated with chronic atrial fibrillation and underlying valvular heart disease in man. J Mol Cell Cardiol. 2006;40(1):173-184.

43. Spodick DH. Arrhythmias during acute pericarditis: a prospective study of 100 consecutive cases. JAMA. 1976;235:39-41.

44. Morgera T, Di Lenarda A, Dreas L, et al. Electrocardiography of myocarditis revisited: clinical and prognostic significance of electrocardiographic changes. Am Heart J. 1992;124:455-467.

45. Maixent JM, Paganelli F, Scaglione J, et al. Antibodies against myosin in sera of patients with idiopathic paroxysmal atrial fibrillation. J Cardiovasc Electrophysiol. 1998;9:612-617.

46. Carnes CA, Chung MK, Nakayama T, et al. Ascorbate attenuates atrial pacing-induced peroxynitrite formation and electrical remodeling and decreases the incidence of postoperative atrial fibrillation. Circ Res. 2001;89:e32-e38.

47. Aviles RJ, Martin DO, Apperson-Hansen C, et al. Inflammation as a risk factor for atrial fibrillation. Circulation. 2003;108:3006-3010.

48. Chung MK, Martin DO, Sprecher D, et al. C-Reactive protein elevation in patients with atrial arrhythmias: inflammatory mechanisms and persistence of atrial fibrillation. Circulation. 2001;104:2886-2891.

49. Shiroshita-Takeshita A, Schram G, Lavoie J, et al. Effect of simvastatin and antioxidant vitamins on atrial fibrillation promotion by atria tachycardia remodeling in dogs. Circulation. 2004;110:2313-2319.

50. Korantzopoulos P, Kolettis TM, Kountouris E, et al. Oral vitamin C administration reduces early recurrence rates after electrical cardioversion of persistent atrial fibrillation and attenuates associated inflammation. Int J Cardiol. 2005a;102:321-326.

51. Korantzopoulos P, Kolettis TM, Kountouris E, et al. Variation of inflammatory indexes after electrical cardioversion of persistent atrial fibrillation: is there an association with early recurrence rates? Int J Clin Pract. 2005b;59:881-885.

52. Kaplan $\mathrm{MH}$, Volanakis JE. Interaction of C-reactive protein complexes with the complement system. I. Consumption of human complement associated with the reaction of C-reactive protein with pneumococcal C-polysaccharide and with the choline phosphatides, lecithin and sphingomyelin. J Immunol. 1974;112:2135-2147.

53. Volanakis JE, Wirtz KW. Interaction of C-reactive protein with artificial phosphatidylcholine bi-layers. Nature. 1979;281:155-157.

54. Blake GJ, Ridker PM. C-reactive protein and other inflammatory risk markers in acute coronary syndromes. J Am Coll Cardiol. 2003; 41 Suppl 4:37S-42S.
55. Conway DS, Buggins $\mathrm{P}$, Hughes E, et al. Predictive value of indexes of inflammation and hypercoagulability on success of cardioversion of persistent atrial fibrillation. Am J Cardiol. 2004a 4:508-510.

56. Conway DS, Buggins P, Hughes E, et al. Relationship of Interleukin-6 and $\mathrm{C}$-reactive protein to the prothrombotic state in chronic atrial fibrillation. J Am Coll Cardiol. 2004b;43:2075-2082.

57. Sata N, Hamada N, Horinouchi T, et al. C-reactive protein and atrial fibrillation: is inflammation a consequence fibrillation? Jpn Heart J. 2004;45:441-445.

58. Psychari SN, Apostolou TS, Sinos L, et al. Relation of elevated C-reactive protein and interleukin-6 levels to left atrial size and duration of episodes in patients with atrial fibrillation. Am J Cardiol. 2005; 95:764-767.

59. Asselbergs FW, van den Berg MP, Diercks GF, et al. C-reactive protein and micro-albuminuria are associated with atrial fibrillation. Int $J$ Cardiol. 2005;98:73-77.

60. Watanabe T, Takeishi Y, Hirono O, et al. C-reactive protein elevation predicts the occurrence of atrial structural remodeling in patients with paroxysmal atrial fibrillation. Heart Vessels. 2005;20: 45-49.

61. Dernellis J, Panaretou M. Relationship between C-reactive protein concentrations during glucocorticoid therapy and recurrent atrial fibrillation. Eur Heart J. 2004;25:1100-1107.

62. Oral H, Knight BP, Ozaydin M, et al. Clinical significance of early recurrences of atrial fibrillation after pulmonary vein isolation. $\mathrm{J} \mathrm{Am}$ Coll Cardiol. 2002;40:100-104.

63. Dernellis J, Panaretou M. Effect of C-reactive protein reduction on paroxysmal atrial fibrillation. Am Heart J. 2005;50:1064.

64. Verheule S, Sato T, Everett T 4th, et al. Increased vulnerability to atrial fibrillation in transgenic mice with selective atrial fibrosis caused by over expression of TGF- $\beta 1$. Circ Res. 2004;94:1458-1465.

65. Wu W, Ke D, Xu CX, et al. Collagen type I and Interleukin-1 beta gene expression in human atria during atrial fibrillation. Zhonghua Nei Ke Za Zhi. 2006;45(10):807-810.

66. Rizos I, Tsiodras S, Rigopoulos AG, et al. Interleukin-2 serum levels variations in recent onset atrial fibrillation are related with cardioversion outcome. Cytokine. 2007;40(3):157-164.

67. Tveit A, Seljeflot I, Grundvold I, et al. Effect of candesartan and various inflammatory markers on maintenance of sinus rhythm after electrical cardioversion for atrial fibrillation. Am J Cardiol. 2007;99(11): 1544-1548.

68. Katoh H, Shimada T, Inoue $\mathrm{S}$, et al. Reduced high serum hepatocyte growth factor levels after successful cardioversion in patients with atrial fibrillation. Clin Exp Pharmacol Physiol. 2004;31(3): 145-151.

69. Atalar E, Haznedaroglu IC, Acil T, Ozer, et al. Patients with paroxysmal atrial fibrillation but not paroxysmal supraventricular tachycardia display evidence of platelet activation during arrhythmia. Platelets. 2003;14(7-8):407-411.

70. Kamath S, Chin BS, Blann AD, et al. A study of platelet activation in paroxysmal, persistent and permanent atrial fibrillation. Blood Coagul Fibrinolysis. 2002;13(7):627-636.

71. Goette A, Jentsch-Ullrich K, Lendeckel U, et al. Effect of atrial fibrillation on hematopoietic progenitor cells: a novel pathophysiological role of the atrial natriuretic peptide? Circulation. 2003; 108(20):2446-2449.

72. Liuba I, Ahlmroth H, Jonasson L, et al. Walfridsson H. Source of inflammatory markers in patients with atrial fibrillation. Europace. 2008;10(7):848-853.

73. Stein A, Wessling G, Deisenhofer I, et al. Systemic inflammatory changes after pulmonary vein radiofrequency ablation do not alter stem cell mobilization. Europace. 2008;10(4):444-449.

74. Marcus GM, Smith LM, Glidden DV, et al. Markers of inflammation before and after curative ablation of atrial flutter. Heart Rhythm. 2008;5(2):215-221.

75. Polyakova V, Miyagawa S, Szalay Z, et al. Atrial extracellular matrix remodeling in patients with atrial fibrillation. J Cell Mol Med. 2008; 12(1):189-208. 
76. Goette A, Arndt M, Röcken C, et al. Calpains and cytokines in fibrillating human atria. Am J Physiol Heart Circ Physiol. 2002;283(1): $\mathrm{H} 264-\mathrm{H} 272$.

77. Gaudino M, Andreotti F, Zamparelli R, et al. The $-174 \mathrm{G} / \mathrm{C}$ Interleukin-6 polymorphism influences postoperative Interleukin-6 Levels and postoperative atrial fibrillation. Is atrial fibrillation an inflammatory complication? Circulation. 2003;108 suppl II: II195-II199.

78. Roldán V, Marín F, Martínez JG, et al. Relation of Interleukin-6 levels and prothrombin fragment $1+2$ to a point-based score for stroke risk in atrial fibrillation. Am J Cardiol. 2005;95(7):881-882.

79. Conway DS, Buggins P, Hughes E, et al. Prognostic significance of raised plasma levels of Interleukin-6 and C-reactive protein in atrial fibrillation. Am Heart J. 2004;148(3):462-466.

80. Lip GY, Patel JV, Hughes E, et al. High-sensitivity C-reactive protein and soluble CD40 ligand as indices of inflammation and platelet activation in 880 patients with nonvalvular atrial fibrillation. Stroke. 2007;38(4):1229-1237.

81. Ferro D, Loffredo L, Polimeni L, et al. Soluble CD40 ligand predicts ischemic stroke and myocardial infarction in patients with nonvalvular atrial fibrillation. Arterioscler Thromb Vasc Biol. 2007;27(12): 2763-2768

82. Li-Saw-Hee FL, Blann AD, Gurney D, et al. Plasma von Willebrand factor, fibrinogen and soluble P-selectin levels in paroxysmal, persistent and permanent atrial fibrillation: effects of cardioversion and return of left atrial function. Eur Heart J. 2001;22: 1741-1747.

83. Marin F, Roldan V, Climent VE, et al. Plasma von Willebrand factor, soluble thrombomodulin, and fibrin D-dimer concentrations in acute onset non-rheumatic atrial fibrillation. Heart. 2004;90: $1162-1166$

84. Yamauchi K, Furui H, Taniguchi N, et al. Plasma beta-thromboglobulin and platelet factor 4 concentrations in patients with atrial fibrillation. Jpn Heart J. 1986;27(4):481-487.

85. Conway DS, Buggins P, Hughes E, et al. Relation of Interleukin-6, C-reactive protein, and the prothrombotic state to transesophageal echocardiographic findings in atrial fibrillation. Am J Cardiol. 2004;93(11):1368-1373, A6.

86. Thambidorai SK, Parakh K, Martin DO, et al. Relation of C-reactive protein correlates with risk of thromboembolism in patients with atrial fibrillation. Am J Cardiol. 2004;94:805-807.

87. Feinberg WM, Pearce LA, Hart RG, et al. Markers of thrombin and platelet activity in patients with atrial fibrillation: correlation with stroke among 1531 participants in the stroke prevention in atrial fibrillation III study. Stroke. 1999;30:2547-2553.

88. Hammwöhner M, Ittenson A, Dierkes J, et al. Platelet expression of CD40/CD40 ligand and its relation to inflammatory markers and adhesion molecules in patients with atrial fibrillation. Exp Biol Med (Maywood). 2007;232(4):581-589.

89. Fukuchi M, Watanabe J, Kumagai K, et al. Increased von Willebrand factor in the endocardium as a local predisposing factor for thrombogenesis in overloaded human atrial appendage. $J$ Am Coll Cardiol. 2001;37:1436-1442.

90. Choudhury A, Freestone B, Patel J, et al. Relationship of soluble CD40 ligand to vascular endothelial growth factor, angiopoietins, and tissue factor in atrial fibrillation. Chest. $2007 \mathrm{Dec} ; 132(6)$ : 1913-1919.

91. Chung NA, Belgore F, Li-Saw-Hee FL, et al. Is the hypercoagulable state in atrial fibrillation mediated by vascular endothelial growth factor? Stroke. 2002;33;2187-2191.

92. Marín F, Corral J, Roldán V, et al. Factor XIII Val34Leu polymorphism modulates the prothrombotic and inflammatory state associated with atrial fibrillation. $J$ Mol Cell Cardiol. 2004 Sep;37(3): 699-704.

93. Herskowitz A, Mayne AE, Willoughby SB, et al. Patterns of myocardial cell adhesion molecule expression in human endomyocardial biopsies after cardiac transplantation. Induced ICAM-1 and VCAM-1 related to implantation and rejection. Am J Pathol. 1994;145:1082-1094.
94. Qiao JH, Ruan XM, Trento A, et al. Expression of cell adhesion molecules in human cardiac allograft rejection. $J$ Heart Lung Transplant. 1992;11:920-925.

95. Taylor PM, Rose ML, Yacoub MH, et al. Induction of vascular adhesion molecules during rejection of human cardiac allografts. Transplantation. 1992;54:451-457.

96. Kamath S, Blann AD, Caine GJ, et al. Platelet P-selectin levels in relation to plasma soluble P-selectin and beta-thromboglobulin levels in atrial fibrillation. Stroke. 2002 May;33(5):1237-1242.

97. Semenov AV, Romanov YA, Loktionova SA, et al. Production of soluble P-selectin by platelets and endothelial cells. Biochemistry (Mosc). 1999;64:1326-1335.

98. Li N, Wallen NH, Hjemdahl P. Evidence for prothrombotic effects of exercise and limited protection by aspirin. Circulation. 1999;100: 1374-1379.

99. Connor CM, Gurbel PA, Serebruany VL. Usefulness of soluble and surface bound P-selectin in detecting platelet activity in patients with congestive heart failure. Am J Cardiol. 1999;83:1345-1349.

100. Jilma B, Blann A, Pernerstorfer T, et al. Regulation of adhesion molecules during human endotoxemia: no acute effects of aspirin. Am J Respir Crit Care Med. 1999;159:857-863.

101. Roldán V, Marín F, Blann AD, et al. Interleukin-6, endothelial activation and thrombogenesis in chronic atrial fibrillation. Eur Heart $J$. 2003;24(14):1373-1380.

102. Shimano M, Tsuji Y, Inden Y, et al. Pioglitazone, a peroxisome proliferator-activated receptor-gamma activator, attenuates atrial fibrosis and atrial fibrillation promotion in rabbits with congestive heart failure. Heart Rhythm. 2008;5(3):451-459.

103. Chello M, Spadaccio C, Patti G, et al. Simvastatin reduces platelet-endocardium adhesion in atrial fibrillation. Atherosclerosis. 2008 Apr; 197(2):588-595.

104. Lee KW, Everett TH 4th, Rahmutula D, et al. Pirfenidone prevents the development of a vulnerable substrate for atrial fibrillation in a canine model of heart failure. Circulation. 2006;114(16):1703-1712.

105. Sawaya SE, Rajawat YS, Rami TG, et al. Down regulation of connexin 40 and increased prevalence of atrial arrhythmias in transgenic mice with cardiac-restricted overexpression of tumor necrosis factor. Am J Physiol Heart Circ Physiol. 2007;292(3): H1561-H1567.

106. Gunaydin S, Ayrancioglu K, Dikmen E, et al. Clinical effects of leukofiltration and surface modification on post-cardiopulmonary. Perfusion. 2007;22:279-288.

107. Amar D, Zhang H, Heerdt PM, et al. Statin use is associated with a reduction in atrial fibrillation after noncardiac thoracic surgery independent of C-reactive protein. Chest. 2005;128(5):3421-3427.

108. Yared JP, Bakri MH, Erzurum SC, et al. Effect of dexamethasone on atrial fibrillation after cardiac surgery: prospective, randomized, double-blind, placebo-controlled trial. $J$ Cardiothorac Vasc Anesth. 2007;21(1):68-75.

109. Chen X, Bing Z, He J, et al. Downregulation of peroxisome proliferator-activated receptor-gamma expression in hypertensive atrial fibrillation. Clin Cardiol. 2009;32(6):337-345.

110. Marcus GM, Whooley MA, Glidden DV, et al. Interleukin- 6 and atrial fibrillation in patients with coronary artery disease: data from the Heart and Soul Study. Am Heart J. 2008;155(2):303-309.

111. Duygu H, Barisik V, Kurt H, et al. Prognostic value of plasma soluble CD40 ligand in patients with chronic non-valvular atrial fibrillation. Europace. 2008;10:210-214.

112. Shan H, Zhang Y, LuY, et al. Downregulation of miR-133 and miR-590 contributes to nicotine-induced atrial remodelling in canines. Cardiovasc Res. 2009;83(3):465-472.

113. Chen CL, Huang SK, Lin JL, et al. Upregulation of matrix metalloproteinase-9 and tissue inhibitors of metalloproteinases in rapid atrial pacing-induced atrial fibrillation. $\mathrm{J} \mathrm{Mol} \mathrm{Cell} \mathrm{Cardiol.}$ 2008;45(6):742-753.

114. Saba S, Janczewski AM, Baker LC, et al. Atrial contractile dysfunction, fibrosis, and arrhythmias in a mouse model of cardiomyopathy secondary to cardiac-specific over expression of tumor necrosis factor- $\alpha . A m$ J Physiol Heart Circ Physiol. 2005;289:H1456-H1467. 
115. Xu J, Ren JF, Mugelli A, et al. Age-dependent atrial remodeling induced by recombinant human Interleukin-11: implications for atrial flutter/fibrillation. J Cardiovasc Pharmacol. 2002;39(3): $435-440$.
116. Gedikli O, Dogan A, Altuntas I, et al. Inflammatory markers according to types of atrial fibrillation. Int $J$ Cardiol. 2007;120(2): 193-197.

\section{Publish your work in this journal}

The Journal of Inflammation Research is an international, peer-reviewed open-access journal that welcomes laboratory and clinical findings on the molecular basis, cell biology and pharmacology of inflammation including original research, reviews, symposium reports, hypothesis formation and commentaries on: acute/chronic inflammation; mediators of inflamma-

\section{Dovepress}

tion; cellular processes; molecular mechanisms; pharmacology and novel anti-inflammatory drugs; clinical conditions involving inflammation. The manuscript management system is completely online and includes a very quick and fair peer-review system. Visit http://www.dovepress.com/ testimonials.php to read real quotes from published authors.

Submit your manuscript here: http://www.dovepress.com/journal-of-inflammation-research-journal 